\title{
How Do Accounting Variables Explain Stock Price Movements? Theory and Evidence ${ }^{a}$
}

\author{
PETER CHEN \\ Hong Kong University of Science \& Technology \\ GUOCHANG ZHANG ${ }^{\mathrm{b}}$ \\ Hong Kong University of Science \& Technology
}

November 2006

Published in Journal of Accounting and Economics (July 2007)

\begin{abstract}
This paper provides theory and evidence showing how accounting variables explain cross-sectional stock returns. Based on Zhang (2000), who relates equity value to accounting measures of underlying operations, we derive returns as a function of earnings yield, equity capital investment, and changes in profitability, growth opportunities and discount rates. Empirical results confirm the predicted roles of all identified factors. The model explains about $20 \%$ of the cross-sectional return variation, with cash-flow-related factors (as opposed to changes in discount rates) accounting for most of the explanatory power. The properties of the model are robust across various subsamples and periods.
\end{abstract}

JEL Classification: M41, G12, G14

Keywords: $\quad$ Stock return, Accounting variables, Earnings yield, Profitability (ROE), Capital investment, Growth opportunity

\footnotetext{
${ }^{a}$ We appreciate the comments of Marc de Bourmont, Murray Carlson, Jerry Feltham, Gilles Hilary, Alan Kraus, Charles Lee, Clive Lennox, Kin Lo (referee), Thomas Lys (Editor), James Ohlson, and workshop participants at Cheung Kong Graduate School of Business, HEC Paris, Hong Kong University of Science and Technology, University of British Columbia, University of California at Berkeley, University of Waterloo, and the 2004 Financial Economics and Accounting Conference at University of Southern California. We gratefully acknowledge financial support from the Research Grants Council of Hong Kong (HKUST6436/05H). All errors are our own.
}

${ }^{\mathrm{b}}$ Correspondence: Guochang Zhang, Department of Accounting, Hong Kong University of Science and Technology, Clear Water Bay, Kowloon, Hong Kong. Phone: (852) 2358 7569; Fax: (852) 2358 1693; Email: acgzhang@ust.hk. 


\section{How Do Accounting Variables Explain Stock Price Movements? Theory and Evidence}

\section{Introduction}

One of the major purposes of accounting is to help investors forecast firms' future cash flows. ${ }^{1}$ If accounting data are informative about fundamental values and changes in values, they should be correlated with stock price changes. However, extensive research thus far has failed to find a strong link between stock performance and accounting measures of performance; for example, earnings variables explain only a small portion of price movements, with the $\mathrm{R}^{2}$ typically less than $10 \%$ for comprehensive cross-sectional samples. ${ }^{2}$ The purpose of this study is to further our understanding of the link between accounting information and equity returns. We first develop a theoretical model relating returns to accounting data that measure a firm's underlying operations. We then empirically evaluate the model's properties and its effectiveness in explaining observed stock returns.

Our return model builds upon the real-options-based valuation model of Zhang (2000), which provides a specific accounting representation of the long-established notion in the finance literature that firm value consists of the value of assets in place plus growth opportunities (e.g., Miller and Modigliani, 1961). Specifically, Zhang (2000) shows that equity value equals the capitalization of earnings from existing assets plus the value of real options that arise from the flexibility to adjust operations (through abandonment or growth). Because equity value hinges on two basic attributes of operations, scale (invested equity capital) and profitability (return on equity), valuation amounts to forecasting the scale and

\footnotetext{
${ }^{1}$ See Statement of Financial Accounting Concept No.1 (FASB, 1978).

${ }^{2}$ See reviews and comments by Lev (1989), Kothari (2001), and Lo and Lys (2000).
} 
profitability of future operations. It follows that stock returns, as changes in value, are related to changes in expectations about the firm's scale and profitability in future periods.

We identify the following four cash-flow-related factors for explaining returns: earnings yield, capital investment, and changes in profitability and growth opportunities. The earnings yield represents contemporaneous value generation and thus constitutes part of the current-period return. Changes in profitability represent changes in operating efficiency (value generation per unit of capital), and thus affect expected future cash flows. Of course, future cash flows also depend on the scale of operations, with the level of capital investment affecting the scale of existing operations, and changes in growth opportunities affecting expected future scale. These cash-flow-related factors combine with the change in the discount rate to form the full set of information associated with returns.

Our model predicts that equity returns are positively related to the four cash flow factors and negatively related to changes in discount rates. Furthermore, due to the convexity properties of real options, changes in profitability and growth opportunities should have a greater effect on returns for firms with higher profitability. In addition to these directional predictions, our model also predicts the coefficient values for both the earnings yield and capital investment.

Since most of the variables in our return model can be measured with publicly available data, the model can be easily estimated and applied in an empirical context. We estimate the return model using a comprehensive set of firm-level data from Compustat for 1983-2001. We find that the signs of the coefficients on all five identified factors are as predicted and highly significant. Furthermore, the coefficients on the profitability and growth opportunity change variables are greater for firms with higher profitability, consistent with the model's predictions. The qualitative properties of the model hold in subsamples partitioned by size, book-to-market, 
and growth, as well as across different periods. Moreover, most of the qualitative properties of the model remain unchanged when we use abnormal returns, rather than total returns, as the dependent variable, with abnormal returns calculated based on the three-factor model of Fama and French (1992, 1993, 1995).

The model explains $17.4 \%$ of the variation of annual stock returns in our pooled crosssectional sample, and approximately $20 \%$ of the variation both in annual samples and in partitioned subsamples. Among the return factors identified by our theory, those related to current and future cash flows (earnings yield, capital investment, and changes in profitability and growth opportunities) play a much greater role in accounting for observed stock price movements — explaining $15.24 \%$ of return variation in the pooled sample — than do changes in the discount rate, which explain only $1.68 \%$ of return variation. Within the set of cash-flow-related factors, profitability-related information (earnings yield and change in profitability) accounts for $11.58 \%$ of return variation in the pooled sample and is thus empirically more important than are scalerelated factors (capital investment and change in growth opportunities), which account for 5.81\% of return variation.

The relation between equity returns and accounting information is one of the most widely researched topics in accounting. A salient feature of existing return studies is the predominant focus on earnings variables. This earnings-based approach can be justified by existing valuation models such as a simple earnings capitalization model or Ohlson’s (1995) linear model. However, as we explain below, these valuation models analyze special economic settings. Moreover, return models that consider only earnings information fail to consider the role of balance sheet data (Patel, 1989). While earnings are an important measure of a firm's operational performance over the reporting period, the balance sheet provides 
information on the amount of capital employed to generate earnings. Indeed, Statement of Financial Accounting Concept (SFAC) No.5, paragraph 24a, states that the income statement “can be interpreted most meaningfully ... only if it is used in conjunction with a statement of financial position, for example, by computing rates of return on assets or equity” (FASB, 1978).

The return model we employ is distinct from earnings-based return models used in prior literature (e.g., Easton and Harris, 1991) in three respects. ${ }^{3}$ First, the setting underlying our return model is more realistic and economically meaningful. As in Zhang (2000), we assume that firms make rational choices by accepting only positive net present value (NPV) projects and by appropriately expanding or contracting the scale of their operations as investment opportunities change. In contrast, the earnings capitalization model, which justifies earnings change as the explanatory factor, is more suited for firms operating in a steady state (so that current earnings are representative of future earnings), and Ohlson's (1995) linear model, which justifies both the earnings level and earnings change as explanatory factors, arises from a context wherein all ongoing capital investment activities have zero NPV (see Lo and Lys, 2000; Biddle, Chen, and Zhang, 2001). ${ }^{4}$

Second, our model incorporates a more comprehensive set of accounting (and nonaccounting) information, and as such it provides a more complete view of how returns are related to accounting information. In our context, existing earnings-based return models can be viewed as

\footnotetext{
${ }^{3}$ Our return model, as well as the models discussed here, focus (primarily) on the role of reported accounting data in explaining returns; they are derived from valuation models that relate equity value to observed accounting data. Another branch of the returns literature focuses on the role of forecasted data. These studies are based upon the original form of the residual income model that relates equity value to expected future accounting data (e.g., Liu and Thomas, 2000; Copeland, Dolgoff, and Moel, 2003).

${ }^{4}$ In such a context, the valuation of current and future investment projects becomes trivial (as they have zero NPV), in which case resource allocation by the capital market has no consequence for wealth generation.
} 
special cases. For example, our theory shows that earnings yield is a valid factor and the (scaled) earnings change (which is correlated with profitability change) should also be a statistically significant explanatory variable. Our theory shows further why earnings variables alone are not adequate, and how returns should also depend on both balance sheet data (such as invested capital) and the characteristics of the firm's external environment (such as growth opportunities and the interest rate). Each of the five factors of our model plays a distinct economic role, and together they form an integrated set of information to explain returns. Our return model explains $17.4 \%$ of the return variation for our pooled sample, compared to $10.01 \%$ with a representative earnings-based model (with scaled earnings and earnings changes as explanatory factors) for the same sample.

Third, compared with previous studies, there is a closer match between the theoretical predictions and empirical results in this study: the qualitative properties of our return model are confirmed by empirical results, the factors identified in theory are all found to be highly significant, and the properties of our model are robust across years and various subsamples. Our model's predictions on coefficient magnitudes also enable us to interpret empirical results against a clear benchmark. ${ }^{5}$

The remainder of the paper proceeds as follows. Section 2 develops a theoretical model of stock returns based on accounting variables. Section 3 describes both the empirical research design and the sample construction. Section 4 provides the main empirical results. In Section 5, we adapt the model to explain abnormal returns (as opposed to total returns). Section 6 summarizes the study.

\footnotetext{
${ }^{5}$ A weakness of extant research is that empirical results are in-sample and there are no predicted values on the earnings coefficients, as pointed out by Kothari (2001).
} 


\section{Modeling the relation between stock returns and accounting fundamentals}

This section establishes the theoretical relation between stock returns and accounting fundamentals and examines the properties of the return function. We begin by introducing the equity value model of Zhang (2000), from which we derive the return function.

\subsection{A model of equity value}

Zhang (2000) develops an equity value model based on (realized) accounting data that measure the characteristics of underlying operations. The model starts by defining value as the present value of future cash flows, and then represents the link between observed accounting data and future cash flows. ${ }^{6}$ Equity value is a function of two basic operational attributes: scale and profitability. Valuation thus amounts to forecasting the scale and profitability of future operations, conditional on current scale and profitability. Profitability (ROE) plays an essential role in this model, as it not only measures a firm's ability to generate value from the invested capital, but also indicates how the firm is likely to adjust the course of operations moving forward. The valuation model embeds the firm's value-creating capital investment decisions within the set of available opportunities as characterized by options to grow and to downsize or abandon. ${ }^{7}$ In what follows, we introduce a simplified version of Zhang's model.

Let $V_{t}$ be the value of an all equity-financed firm at date $t$ (end of period $t$ ). $B_{t}$ is the corresponding book value of equity, which measures the amount of (equity) capital invested in the firm, $X_{t}$ is the earnings generated in period $t$, and $g_{t}$ is the firm's growth opportunities as perceived at $t$, defined as the percentage by which the scale of operations (capital invested) may grow.

\footnotetext{
${ }^{6}$ This is a standard approach in the accounting-based valuation literature (e.g., Ohlson, 1995; Feltham and Ohlson, 1995, 1996).

${ }^{7}$ That real options constitute part of firm value has been widely recognized in both the finance literature (e.g., Myers, 1977; Berger, Ofek, and Swary, 1996; Brennan and Schwartz, 1985; and Berk, Green, and Naik, 1999) and the accounting literature (e.g., Burgstahler and Dichev, 1997).
} 
Define $q_{t} \equiv X_{t} / B_{t-1}$ as period $t$ profitability (ROE). Then, following Zhang (2000), equity value can be expressed as

$$
V_{t}=k E_{t}\left(X_{t+1}\right)+B_{t} P\left(q_{t}\right)+B_{t} g_{t} C\left(q_{t}\right),
$$

where $E_{t}\left(X_{t+1}\right)$ is the expected next-period earnings to be generated from the assets in place, $k$ is the earnings capitalization factor, and $P\left(q_{t}\right)$ and $C\left(q_{t}\right)$ are, respectively, the put option to abandon operations and the call option to expand operations, both normalized by the scale of operations $\left(B_{t}\right) .{ }^{8}$ The option values relate to the benefit from, and likelihood of, exercising the options, and are functions of profitability. Intuitively, (1) states that equity value equals the value of maintaining the existing operations (capitalization of earnings from existing assets) plus the value of any growth and abandonment options. The relative importance of the different components in (1) depends on the firm's profitability $\left(q_{t}\right)$ and growth opportunities $\left(g_{t}\right)$.

To simplify the analysis, we further assume that profitability follows a random walk, $\tilde{q}_{t+1}=q_{t}+\tilde{e}_{t+1}$, where $\tilde{e}_{t+1}$ is a zero-mean disturbance term. ${ }^{9}$ Then, $E_{t}\left(X_{t+1}\right)=E_{t}\left(B_{t} q_{t+1}\right)=B_{t} q_{t}$, and $k=1 / r_{t}$, where $r_{t}$ is the discount rate at $t$. Thus, valuation function (1) becomes

$$
V_{t}=B_{t}\left[q_{t} / r_{t}+P\left(q_{t}\right)+g_{t} C\left(q_{t}\right)\right] \equiv B_{t} * v\left(q_{t}, g_{t}, r_{t}\right),
$$

where $v\left(q_{t}, g_{t}, r_{t}\right) \equiv q_{t} / r_{t}+P\left(q_{t}\right)+g_{t} C\left(q_{t}\right)$. According to (2), the equity value can be viewed as a product of two basic elements: the amount of (equity) capital invested, $B_{t}$, and the value per unit of capital, $v$, which is a function of profitability $\left(q_{t}\right)$, growth opportunities $\left(g_{t}\right)$, and the discount rate $\left(r_{t}\right)$.

\footnotetext{
${ }^{8}$ See Zhang (2000) for mathematical expressions of $C\left(q_{t}\right)$ and $P\left(q_{t}\right)$.

${ }^{9}$ The same qualitative results obtain for any process that implies a positive correlation between current and future profitability, including mean-reversion processes. Such a positive correlation is widely documented in previous studies (e.g., Fama and French, 2000; Biddle, Chen, and Zhang, 2001).
} 
As Zhang (2000) shows, $v$ is an increasing and convex function of $q_{t}$. When profitability is sufficiently low, the firm will limit operating losses by abandoning operations and diverting the resources to alternative uses. As profitability increases, the likelihood that the firm will remain in operation increases, as does firm value. With higher profitability, not only are the existing assets more productive, but the growth option becomes more valuable. The flexibility to scale down operations when profitability is low and to scale up operations when profitability is high makes the valuation function convex in $q_{t .}{ }^{10}$

It can also be shown that while $v$ increases with growth opportunities $g_{t}$, the effect of $g_{t}$ is concentrated mostly in high-profitability regions, that is, the regions in which the growth option is “in the money.” Finally, $v$ decreases with discount rate $r_{t}$, which prices future cash flows.

\subsection{A model of stock returns}

To derive the return function, we consider the change in equity value from date $t$ to date $t^{+1}$ (period $t+1$ ), which we denote $\Delta V_{t+1}$ (similar notation applies for changes in other variables).

Taking changes on both sides of (2), we obtain ${ }^{11}$

$$
\Delta V_{t+1} \approx \Delta B_{t+1} v\left(q_{t}, g_{t}, r_{t}\right)+B_{t}\left[v_{1} \Delta q_{t+1}+C\left(q_{t}\right) \Delta g_{t+1}+v_{3} \Delta r_{t+1}\right],
$$

where $v_{l} \equiv d v / d q_{t}$ and $v_{3} \equiv d v / d r_{t}$. Note that $d v / d g_{t}=C\left(q_{t}\right)$.

Let $D_{t+1}$ be the dividends paid in period $t+1$, net of capital contribution. The period $t+1$ stock return, denoted $R_{t+1}$, equals

\footnotetext{
${ }^{10}$ The convexity property of Zhang's model is demonstrated in a partial equilibrium setting in which industry competition is not considered. More generally, when a firm enjoys high profitability, it may attract more firms to enter the industry, causing future profitability to decline; this would dampen or offset the convexity of the valuation function.

${ }^{11}$ This is an approximate relation that follows from the Taylor series expansion. We ignore the secondand higher-order terms in the analysis. Empirically, these higher-order terms are found to have little effect on returns.
} 


$$
\begin{aligned}
R_{t+1} & \equiv \frac{\Delta V_{t+1}+D_{t+1}}{V_{t}} \\
& =v\left[\frac{\Delta B_{t+1}}{V_{t}}\right]+v_{1}\left[\frac{B_{t}}{V_{t}} \Delta q_{t+1}\right]+C\left(q_{t}\right)\left[\frac{B_{t}}{V_{t}} \Delta g_{t+1}\right]+v_{3}\left[\frac{B_{t}}{V_{t}} \Delta r_{t+1}\right]+\frac{D_{t+1}}{V_{t}} \\
& =\frac{\Delta B_{t+1}}{B_{t}}+v_{1}\left[\frac{B_{t}}{V_{t}} \Delta q_{t+1}\right]+C\left(q_{t}\right)\left[\frac{B_{t}}{V_{t}} \Delta g_{t+1}\right]+v_{3}\left[\frac{B_{t}}{V_{t}} \Delta r_{t+1}\right]+\frac{D_{t+1}}{V_{t}}
\end{aligned}
$$

Assuming the clean surplus relation, $\Delta B_{t+1}=X_{t+1}-D_{t+1}$, we have $D_{t+1}=X_{t+1}-\Delta B_{t+1}$. Replacing dividends $D_{t+1}$ in (4) with the accounting variables $X_{t+1}$ and $\Delta B_{t+1}$ and rearranging, we obtain the following function for the period $t+1$ return:

$$
R_{t+1}=\left[\frac{X_{t+1}}{V_{t}}\right]+v_{1}\left[\frac{B_{t}}{V_{t}} \Delta q_{t+1}\right]+\left[\left(1-\frac{B_{t}}{V_{t}}\right) \frac{\Delta B_{t+1}}{B_{t}}\right]+C\left(q_{t}\right)\left[\frac{B_{t}}{V_{t}} \Delta g_{t+1}\right]+v_{3}\left[\frac{B_{t}}{V_{t}} \Delta r_{t+1}\right]
$$

Equation (5) shows that the stock return over period $t+1$ is a function of the following five factors: i) the contemporaneous earnings yield $\left(X_{t+1} / V_{t}\right)$, ii) the change in profitability $\left(\Delta q_{t+1}\right)$, iii) the change in equity capital $\left(\Delta B_{t+1} / B_{t}\right)$, which we refer to as (equity) capital investment, iv) the change in growth opportunities $\left(\Delta g_{t+1}\right)$, and v) the change in the discount rate $\left(\Delta r_{t+1}\right)$.

We classify the earnings yield and the change in profitability as profitability-related information, and capital investment and the change in growth opportunities as scale-related information; together, these factors form the basis for revising expectations about future cash flows. Further, we complement these cash flow factors with the change in the discount rate to form the full information set in the model. Intuitively, then, (5) states that returns relate to contemporaneous value generation and changes in expectations about future value generation as conveyed by expected changes in the scale and profitability of operations, adjusted for the effect of changes in the discount rate.

\subsection{Return factors and their predicted coefficients}


Earnings yield $\left(X_{t+1} / V_{t}\right)$ : Earnings $\left(X_{t+1}\right)$ represent the value generated in the current period (period $t+1)$. Earnings normalized by the beginning-of-period equity value $\left(V_{t}\right)$ constitute part of the stock return. According to (5), the coefficient on $X_{t+1} / V_{t}$ is positive, conditional on the other factors identified in the model.

Change in profitability $\left(\Delta q_{t+1}\right)$ : Since profitability is central to value generation, the change in profitability is central to returns. The model requires that $\Delta q_{t+1}$ be adjusted by the (beginning-of-period) book-to-market ratio, $B_{t} / V_{t}$, in the return function. This is because profitability changes affect value generation through invested capital $\left(B_{t}\right)$, whereas returns are defined relative to beginning-of-period market value $\left(V_{t}\right)$. The coefficient on $\Delta q_{t+1}$ (after adjusting by the book-to-market ratio) is $v_{l}$ (i.e., $d v / d q_{t}$ ), which is an increasing function of $q_{t}$ given that $v$ is an increasing and convex function of $q_{t}$. Also, the coefficient on $\Delta q_{t+l}$ is expected to be positive for all levels of profitability.

Capital investment $\left(\Delta B_{t+1} / B_{t}\right)$ : Capital investment, defined as the proportional change in invested equity capital, $\Delta B_{t+1} / B_{t}$, affects returns because it changes the capital base on which value is generated. The model requires that $\Delta B_{t+1} / B_{t}$ be adjusted by $\left(1-B_{t} / V_{t}\right)$, reflecting the fact that returns relate to net value creation from invested capital over and above the cost of capital. The intuition is as follows: An increase in the capital base (i.e., scale) that derives from incremental capital investment raises expectations about the amount of future value generation, and this alone increases equity value. However, incremental capital investment also reduces the current period's dividends. The coefficient on $\Delta B_{t+1} / B_{t}$ captures the net result of these two effects; this coefficient is predicted to be positive provided that, on average, firms make positive NPV investments. 
Change in growth opportunities $\left(\Delta g_{t+1}\right)$ : Because value depends on growth opportunities (i.e., the extent to which the operating scale can potentially grow), returns should depend on changes in growth opportunities. Ceteris paribus, a positive growth opportunity shock increases equity value and hence returns. The impact of $\Delta g_{t^{+l}}$ on returns is predicted to be greater for firms that have higher profitability (i.e., are more capable of exploiting external opportunities). The model specifies that $\Delta g_{t+1}$ should be adjusted by $B_{t} / V_{t}$ (for the same reason as explained above). The coefficient on $\Delta g_{t+1}$, after adjusted by $B_{t} / V_{t}$, is $C\left(q_{t}\right)$, which is positive and increasing in $q_{t}$.

Change in the discount rate $\left(\Delta r_{t+1}\right)$ : The discount rate determines how future cash flows are priced. An increase in the discount rate reduces the present value of future cash flows, which in turn lowers equity values and returns. Thus, the coefficient on $\Delta r_{t}, v_{3}$, is predicted to be negative.

\section{Empirical research design and data}

\subsection{Empirical research design}

Our empirical analysis focuses primarily on the relation between realized total stock returns and accounting variables. This relation follows directly from the theoretical model above. In Section 5, we examine how accounting information explains abnormal returns.

According to the theoretical model presented in (5), the coefficient on $\Delta q$ relates to the first-order derivative of the growth option, and the coefficient on $\Delta g$ relates to the growth option. Both coefficients are increasing functions of profitability, which means that they are expected to vary from firm to firm. In this study, we focus not on providing firm-level estimations of realoption values, but rather on capturing some of the qualitative properties of real options. 
We estimate two empirical versions of the return model. The first version is a linear specification intended to provide a first approximation of model (5). Specifically, the first version is given by

$$
R_{i t}=\alpha+\beta x_{i t}+\gamma \Delta \hat{q}_{i t}+\delta \Delta \hat{b}_{i t}+\omega \Delta \hat{g}_{i t}+\varphi \Delta \hat{r}_{i t}+e_{i t},
$$

where $R_{i t}$ is the annual stock return of firm $i$ in year $t$, measured from two days after the year $t-1$ earnings announcement to one day after the year $t$ earnings announcement; $x_{i t}=X_{i t} / V_{i t-l}$ is the earnings yield of firm $i$ in year $t$, computed as the earnings to common shareholders in year $t\left(X_{i t}\right)$ (Compustat data item \#237) divided by the beginning-of-period market value of equity $\left(V_{i t-1}\right)$; $\Delta \hat{q}_{i t}=\left(q_{i t}-q_{i t-1}\right) B_{i t-1} / V_{i t-1}$ is the change in profitability of firm $i$ in year $t$, adjusted by the beginningof-period ratio of the book value of equity (item \# 60) to the market value of equity, with profitability defined as the return on equity, $q_{i t}=X_{i t} / B_{i t-1} ; \Delta \hat{b}_{i t}=\left[\left(B_{i t}-B_{i t-1}\right) / B_{i t-1}\right]\left(1-B_{i t-1} / V_{i t-1}\right)$ is (equity) capital investment, or the proportional change in the book value of equity of firm $i$ in year $t$, adjusted by one minus the beginning-of-period book-to-market ratio; $\Delta \hat{g}_{i t}=\left(g_{i t}-g_{i t-1}\right) B_{i t-1} / V_{i t-1}$ is the change in growth opportunities of firm $i$ in year $t$, adjusted by the beginning-of-period bookto-market ratio; $\Delta \hat{r}_{i t}=\left(r_{t}-r_{t-1}\right) B_{i t-1} / V_{i t-1}$ is the change in the discount rate in year $t$ (the same period over which firm $i$ 's return is calculated), adjusted by firm $i$ 's beginning-of-period book-to-market ratio; $\alpha, \beta, \gamma, \delta, \omega$, and $\varphi$ are regression coefficients; and $e_{i t}$ is a residual term. The theoretical predictions are $\beta=1, \gamma>0, \delta=1, \omega>0$, and $\varphi<0$.

The second version of the return model is a piecewise linear regression, which allows the coefficients of $\Delta \hat{q}$ and $\Delta \hat{g}$ to vary across firms with different levels of profitability (implied by the properties of real options). Specifically, the second version is 


$$
\begin{aligned}
R_{i t} & =\alpha+\beta x_{i t}+\gamma \Delta \hat{q}_{i t}+\gamma_{M} M \Delta \hat{q}_{i t}+\gamma_{H} H \Delta \hat{q}_{i t} \\
& +\delta \Delta \hat{b}_{i t}+\omega \Delta \hat{g}_{i t}+\omega_{M} M \Delta \hat{g}_{i t}+\omega_{H} H \Delta \hat{g}_{i t}+\varphi \Delta \hat{r}_{i t}+e_{i t},
\end{aligned}
$$

where $M$ and $H$ are, respectively, dummy variables for the middle- and high-third profitability ranges of a sample. The coefficients on the dummy terms represent the incremental slope coefficients for the higher-profitability ranges over and above that for the low-profitability range. The theoretical predictions are $\gamma_{H}>\gamma_{M}>0$ and $\omega_{H}>\omega_{M}>0$. The predictions on the other coefficients in (7) remain the same as those in (6).

Existing studies mainly rely on earnings variables to explain stock returns. To examine whether, and to what extent, our return model offers improvements over existing models in explaining return data, we compare regressions (6) and (7) against the following earnings-based model often used in the literature: ${ }^{12}$

$$
R_{i t}=\alpha+\beta x_{i t}+\lambda \Delta x_{i t}+e_{i t},
$$

where $\Delta x_{i t}=\left(X_{i t}-X_{i t-1}\right) / V_{i t-1}$ is firm $i$ 's change in earnings in period $t$ divided by its beginning-ofperiod $t$ market value.

\subsection{Data}

Of the five factors in return model (5), data for the first three (earnings yield, change in profitability, and capital investment) are readily available from reported financial statements. Growth opportunities are not observable. We use the consensus analyst forecast of the firm's long-term growth rate as a proxy, ${ }^{13}$ and revisions of the consensus forecast as a proxy for changes

\footnotetext{
${ }^{12}$ See, among others, Easton and Harris (1991), Ali and Zarowin (1992), Ely and Waymire (1999), Francis and Schipper (1999), and Lev and Zarowin (1999).

${ }^{13}$ Previous studies have used beginning market-to-book ratio as a proxy for growth opportunity. We eschew using this measure to avoid the circularity of relying on the change in market-to-book ratio to explain changes in market value (returns). It has been suggested that forecasts of long-term growth tend to be optimistically biased (e.g., Chan et al., 2001), but the bias should be less of a concern in our study as we use change (not level) of forecast as a regression variable.
} 
in growth opportunities. We use the change in the yield on ten-year U.S. government bonds as a proxy for the change in the discount rate.

We extract annual stock returns from CRSP daily files for all firms with annual earnings announcement dates available in the Compustat quarterly file. Earnings and equity book values are from the Compustat annual file, and consensus analyst forecasts of long-term earnings growth are from the I/B/E/S database. The sample is the intersection of these three data sets for 1983$2001{ }^{14}$ To ensure that the growth opportunity measure impounds the current year's earnings information, we take the first consensus forecast available after an annual earnings announcement. We exclude observations with negative book equity and trim $0.5 \%$ of the extreme observations at the top and bottom ends of the distribution for each of the following variables: $R, x, \Delta b, \Delta q$, and $\Delta g$. The final sample consists of 27,897 firm-year observations.

\subsection{Descriptive statistics}

Panel A of Table 1 presents the descriptive statistics of the overall pooled sample. The mean (median) annual return is 15\% (10\%). The mean (median) factor estimates are as follows: earnings yield, 6\% (7\%), implying a price-to-earnings ratio of 16.7 (14.3); change in annual profitability, $-1.55 \%$ (-0.01\%); capital investment (proportional change in equity capital), 13\% (10\%); change in growth opportunities (i.e., revision of consensus analyst forecasts of the longterm growth rate), $-0.53 \%(-0.09 \%)$; change in the discount rate, $-0.29 \%(-0.51 \%)$. The mean (median) beginning book-to-market ratio is $0.59(0.53)$.

[Table 1 about here]

Panel B of Table 1 reports the statistics of the annual samples. The mean annual stock return fluctuates widely from year to year, ranging from a low of $-6 \%$ in 1987 and to a high of 
35\% in 1991. The mean return does not exhibit an obvious increasing or decreasing trend over time, though the variability of returns across firms becomes greater in more recent years.

The mean earnings yield observes a slow declining trend from 1983 to 2001, ranging from $10 \%$ in 1983 to 3\% in 1998 and 2001. The mean change in profitability fluctuates between $-3.07 \%$ and $0.66 \%$ and is typically below the median value, suggesting the presence of extreme low values in annual samples. Mean capital investment remains relatively steady, ranging between 8\% in 1984 and 19\% in 1995, although increasing slightly in more recent years. While the mean change in growth opportunities is negative for all years except for 1983, the median is zero for about half of the years and negative for the remaining years. The mean change in the discount rate varies from $-2.63 \%$ to $1.45 \%$. Finally, the mean book-to-market ratio exhibits a declining trend, ranging between 0.44 in 1998 and 0.87 in 1983.

Panel C of Table 1 shows the correlation coefficients among the variables. Stock return $(R)$ has a significant correlation with all five explanatory factors identified by the theory. Return is positively correlated with the four cash-flow-related factors (earnings yield, capital investment, and changes in profitability and growth opportunities) and negatively correlated with the discount rate change, consistent with the theoretical predictions. The four cash flow factors are positively correlated with each other. The discount rate change is not correlated with earnings yield or capital investment, but it is positively correlated with changes in profitability and growth opportunities.

\section{Main empirical results}

In this section, we estimate the two empirical versions of our return model, (6) and (7), and examine their empirical properties. We also compare the performance of our model to that of

\footnotetext{
${ }^{14}$ Long-term earnings growth forecasts are available in the I/B/E/S database for 1982 forward. For each
} 
benchmark earnings-based model (8). Below, we present results from the pooled sample, annual samples, and subsamples partitioned by size, book-to-market, and growth.

\subsection{Results from the pooled sample}

\subsubsection{Estimation of the return model}

Table 2 reports the pooled sample results for regression equations (6) and (7). All five factors are significantly different from zero at the $1 \%$ level, and the signs on the slope coefficients are consistent with the predictions of the theoretical model. Specifically, returns are positively related to earnings yield, capital investment, and changes in profitability and growth opportunities, and negatively related to the change in the discount rate. The (adjusted) $\mathrm{R}^{2}$ is $16.01 \%$ for linear regression (6), and $17.4 \%$ for piecewise linear regression (7).

[Table 2 about here]

The coefficient on earnings yield $(x)$ is $0.97(t=27.71)$ in the linear model and 1.09 $(t=30.79)$ in the piecewise linear model, both significantly different from zero at the $1 \%$ level. Furthermore, the estimate in the linear model is not significantly different from the predicted value of one at the $5 \%$ level $(t=0.86)$. The estimate in the piecewise linear model is significantly different from one at the $5 \%$ level $(\mathrm{t}=2.54)$.

The change in profitability $(\Delta \hat{q})$ has a coefficient of $0.76(t=20.34)$ in the linear regression, significantly different from zero at the $1 \%$ level. In the piecewise linear regression, the coefficient is 0.32 ( $t=7.37$ ) for the low-profitability range, significantly different from zero, and increases to 1.62 in the middle-profitability range and 1.67 in the high-profitability range. The incremental slope coefficients for the middle- and high-profitability ranges, relative to the low range, are 
significant at the $1 \%$ level ( $t=13.54$ and 15.30 , respectively), confirming that the impact of a profitability change on returns is greater in higher profitability ranges.

Based on the linear version of the return model, the coefficient estimate for $\Delta \hat{q}$ implies that, on average, a profitability (ROE) increase of $1 \%$ increases stock prices by $0.45 \%$ for the pooled sample (assuming a sample average book-to-market ratio of 0.59). However, according to the piecewise linear regression, this effect differs substantially for firms with different profitabilities: the average price increase associated with a $1 \%$ increase in ROE is $0.19 \%$ in the low-profitability range, $0.96 \%$ in the medium range, and $0.99 \%$ in the high range.

Capital investment ( $\Delta \hat{b}$, adjusted by $1-B / V$ ) has a coefficient of 0.31 in both the linear and piecewise linear regressions, significantly different from zero at the $1 \%$ level $(t=23.38$ and $t=23.35$, respectively). Thus, with a book-to-market ratio of 0.59 and a given level of earnings, a $1 \%$ increase in the capital base (at the expense of current dividends) is associated with an incremental return of $0.13 \%$. The coefficient is significantly positive, suggesting that, on average, capital investments lead to positive (net) value creation. However, the estimated coefficient of 0.31 is significantly below the theoretical value of one ( $t=52.04$ and $t=51.97$ in the linear and piecewise linear regressions, respectively). ${ }^{15}$

The change in growth opportunities ( $\Delta \hat{g})$ has a coefficient of $2.97(t=26.17)$ in the linear regression, significantly different from zero at the $1 \%$ level. This means that, ceteris paribus, a $1 \%$ increase in growth opportunities (as measured by the forecasted long-term earnings growth rate) leads to an average increase in equity value of $1.75 \%$ (assuming a book-to-market ratio of 0.59 ). In the piecewise linear regression, the coefficient on the change in growth is $2.49(t=17.54)$ in the

\footnotetext{
${ }^{15}$ This discrepancy may be caused by diminishing returns to scale, with returns earned on incremental investments below those on existing assets. The assumption of constant returns to scale (up to a certain point) is maintained in the model of Zhang (2000).
} 
low-profitability range, significantly different from zero, and increases to 2.69 in the medium range and 5.34 in the high range. The increase in the coefficient is not significant for the middleprofitability range $(t=0.74)$, but is significant for the high range $(t=8.61)$. The results are generally consistent with the prediction that the impact of a change in growth opportunities on returns is greater for firms with higher profitability.

Finally, the coefficient on the change in the discount rate $(\Delta \hat{r})$ is -0.08 in both regressions, and is significantly different from zero at the 1\% level ( $t=-27.52$ and $t=-27.11$ in the linear and piecewise linear regressions, respectively). This implies that, on average, a $1 \%$ increase in the discount rate causes stock prices to drop by $4.72 \%$ (assuming a book-to-market ratio of 0.59 ).

\subsubsection{Comparison with the benchmark model}

Table 2 also reports the empirical results for the benchmark model (8), which uses the earnings yield $(x)$ and the scaled earnings change $(\Delta x)$ to explain returns. The coefficients on earnings yield and earnings change are $1.21(t=37.26)$ and $0.64(t=21.57)$, respectively; both are significant at the $1 \%$ level, consistent with prior findings.

The adjusted $\mathrm{R}^{2}$ of benchmark model (8) is $10.01 \%$, compared with our adjusted $\mathrm{R}^{2} \mathrm{~s}$ of 16.01\% for model (6) and 17.41\% for model (7). Vuong's Z-test indicates that the difference between our model (proxied by either (6) or (7)) and the benchmark model (8) is significant at the 1\% level (Z=14.53 comparing (6) with (8); Z=16.17 comparing (7) with (8)).

Empirically, the change in profitability ( $\Delta \hat{q}$ ) in our models (6) and (7) and the scaled earnings change ( $\Delta x)$ in benchmark model (8) are highly correlated (0.823). ${ }^{16}$ If we replace $\Delta x$ in (8) with $\Delta \hat{q}$ and run the following regression (used as a modified benchmark model),

\footnotetext{
16 The extent to which the earnings change differs from the change in profitability depends on the level of equity capital investment (change in book value) during a period. In a sample in which firms' end-of-
} 


$$
R_{i t}=\alpha+\beta x_{i t}+\lambda \Delta \hat{q}_{i t}+e_{i t},
$$

the results (shown in Table 2) are similar to those associated with (8) in terms of coefficient significance and $\mathrm{R}^{2}$, and we conclude that our return model outperforms the modified benchmark model ( $Z=14.26$ comparing (6) with (9), and $Z=15.94$ comparing (7) with (9), both significant at the $1 \%$ level). ${ }^{17}$

Regression models (6) to (9) may be viewed as all being nested in a comprehensive model whose explanatory variables encompass the five factors in our theoretical model (5) and factor $\Delta x$. As these factors are correlated, regressions that rely only on a subset of these factors, such as models (6) to (9), may be mis-specified due to omitted correlated variables. However, our further analysis shows that after adding $\Delta x$ to our five factors in (7) (to form the most encompassing model), $\Delta x$ is insignificant at the 0.05 level (the t-value is 0.12 in the pooled-sample regression and the Fama-MacBeth t-value is 0.30 from annual regressions); at the same time, the significance of our five factors remains unchanged and the model's explanatory power is little affected. This suggests that $\Delta x$ has little incremental usefulness beyond our five fundamental factors. ${ }^{18}$ Given this result, we can view model (7) as the "comprehensive” model within our context, with model (6) serving as a linear approximation of (7); consequently, the comparisons made above between our empirical return models (regressions (6) and (7)) and the benchmark model (regression (8)) are valid.

period book values do not differ drastically from their beginning-of-period values, the scaled earnings change approximately equals the change in profitability.

${ }^{17}$ Comparing (8) with (9), we notice a slight increase in the $\mathrm{R}^{2}$, and Vuong's Z-statistic is 2.70, significant at the $1 \%$ level, suggesting that $\Delta \hat{q}$ offers more explanatory power than $\Delta x$.

${ }^{18}$ Variable $\Delta x$ is also insignificant at the 0.05 level when it is added to our linear model (6), both in the pooled-sample regression and in the Fama-MacBeth test. 


\subsection{Results from annual samples}

\subsubsection{Estimation of the return model}

Table 3 presents the return model estimations using annual samples, with the results that correspond to linear regression (6) in Panel A and those that correspond to piecewise linear regression (7) in Panel B. The average coefficients, shown at the bottom of the panels, are calculated based upon annual results, and their statistical significances are indicated by FamaMacBeth $t$-values. Overall, the qualitative properties that obtain for the pooled sample also hold for the annual samples, though the magnitudes of the coefficient estimates vary somewhat from year to year (described in detail below).

[Table 3 about here]

The average coefficient on the earnings yield using annual samples is 0.90 ( $t=5.65)$ in the linear model and $1.01(t=6.41)$ in the piecewise linear model, both significant at the $1 \%$ level. ${ }^{19}$ Interestingly, the average coefficient is not significantly different from the theoretical value of one at the $5 \%$ level in either specification ( $t=0.63$ and $t=0.06$, respectively). For individual years, the coefficient on earnings yield is positive and significant at the $1 \%$ level for 16 (17) of the 19 years in the linear (piecewise linear) regression model, positive but insignificant for two years (one year), and negative for one year (1999). ${ }^{20}$

The average coefficient on the change in profitability is $0.77(t=7.80)$ in the linear specification and significant. In the piecewise linear specification, the average coefficient on this factor is 0.36 ( $t=3.67$ ) for the low-profitability range, significant at the $1 \%$ level, increasing to 1.45 for the medium-profitability range and 1.63 for the high-profitability range. The coefficient

\footnotetext{
${ }^{19}$ The significances of the average coefficients of the annual regressions are determined based on the Fama-MacBeth approach.
} 
increases from the low-profitability range to the medium- and high-profitability ranges are both significant at the $1 \%$ level ( $t=8.91$ and $t=7.59$ respectively). For individual years, the coefficient on the change in profitability in the linear model is positive for all 19 years and significant in 17 of the 19 years. In the piecewise linear regressions, the base coefficient on the change in profitability, obtained from the low-profitability range, is generally positive (17 of 19 years, significant at the $1 \%$ level in seven years). This coefficient increases as we move to higher profitability regions. The incremental coefficient for the medium range is positive in all years and that for the high-profitability range is positive in 18 years (significant in 14 years in both cases). These results are consistent with the theoretical prediction that the effect of a change in profitability on returns is positive, and is greater for firms with higher profitabilities.

The average coefficient on capital investment is $0.31(t=5.71)$ in the linear regression and $0.30(t=5.49)$ in the piecewise linear regression, both significant at the $1 \%$ level. However, similar to the pooled sample results above, the magnitude of the coefficient is significantly below the theoretical value of one in both the linear regression $(t=12.71)$ and piecewise linear regression ( $t=12.81$ ), possibly due to diminishing returns to scale. For individual years, the coefficient is positive in all but two of the years, and significant in 15 years. This suggests that, on average, capital investment has a positive (i.e., value-creating) impact on returns.

Based on the linear specification, the average coefficient on the change in growth opportunities is 2.93 ( $t=12.36)$, significant at the $1 \%$ level. This coefficient is positive in all 19 individual years, and significant in all years except 1987. In the piecewise linear regressions, the average coefficient on the change in growth opportunities is $2.46(t=11.47)$ in the low-profitability range, significant at the $1 \%$ level. The average incremental coefficient is $0.35(t=0.91)$ for the

\footnotetext{
${ }^{20}$ The significantly negative coefficient on the earnings yield for 1999 could be due to the surge in high-
} 
medium-profitability range, insignificantly different from zero, and $2.79(t=5.67)$ for the highprofitability range, significant at the $1 \%$ level. For individual years, the coefficient is significantly positive for the low-profitability range in all years except for 1987; the incremental coefficient generally fluctuates around zero and is insignificant for the medium-profitability range, and generally is positive (in 16 years) and significant (in seven years) for the high-profitability range. The results show that the impact of growth opportunity shocks on returns are positive and of a similar magnitude in the low- and medium-profitability ranges but the impact is greater in the high-profitability range, consistent with the theoretical prediction.

The negative relation between returns and changes in the discount rate is generally confirmed. The average coefficient is -0.07 in both specifications, significant at the $5 \%$ level $(t=-$ 2.41 and $t=-2.50$, respectively). Moreover, in both specifications, the coefficient on the change in the discount rate is negative in 14 of the 19 years, significant at the $1 \%$ level in ten of the 14 years. In the remaining five years, the coefficient has a positive sign.

The annual $\mathrm{R}^{2}$ ranges from $8.94 \%$ (1987) to $32.92 \%$ (1984) for linear regression (6), with an average of $19.65 \%$, and from $10.43 \%$ to $35.15 \%$ for piecewise linear regression (7), with an average of $21.67 \%$.

\subsubsection{Comparison with the benchmark model}

Table 3, Panel C, presents the results for the earnings-based benchmark model (8) using annual samples. As for the pooled sample, the coefficients on earnings and changes in earnings are generally positive and significant. The average coefficients for the annual regressions are 1.07 $(t=7.50)$ for the earnings yield and 0.75 ( $t=6.83)$ for the change in earnings, both significantly

tech stocks in that year when those firms produced little or negative earnings. 
different from zero at the $1 \%$ level. The annual $\mathrm{R}^{2}$ ranges from $5.63 \%$ to $27.58 \%$, with an average of $13.26 \%$.

Compared with benchmark model (8), the two versions of our return model, (6) and (7), offer substantially higher explanatory power. The average $\mathrm{R}^{2} \mathrm{~s}$ of regressions (6) and (7) using annual samples are $19.65 \%$ and $21.67 \%$, respectively, versus $13.26 \%$ for the benchmark model (8). Furthermore, in all 19 years, the adjusted $R^{2} s$ of (6) and (7) are higher than that of (8), and the differences are significant at the $1 \%$ level in all years based on Vuong’s Z-test.

\subsection{Robustness checks on various subsamples}

To verify the robustness of the results obtained from the pooled and annual samples above, we now analyze various partitions of the sample. ${ }^{21}$ The results for this subsection are not tabulated but are available upon request.

We first partition the pooled sample into deciles based upon the book-to-market ratio and run separate regressions. The results show that in all book-to-market deciles, the regression coefficients have the same signs as predicted by the theoretical model, suggesting that the qualitative properties of our return model are robust across different book-to-market groups. The adjusted $\mathrm{R}^{2}$ of the model remains steady as book-to-market changes, ranging from $17.2 \%$ in decile 10 (highest book-to-market) to 23.41\% in decile 2, with an average of $20.0 \%$.

Next we partition the overall sample into deciles based upon firm size (measured by the beginning-of-period market value of equity) and again run separate regressions. The coefficient signs in the pooled and annual samples above are unchanged for all size groups. The adjusted $\mathrm{R}^{2}$ of the return model remains steady as size changes, ranging from $15.5 \%$ to $21.8 \%$, with an

\footnotetext{
${ }^{21}$ The results we discuss here are based on linear specification (6). Similar results obtain for piecewise linear regression (7).
} 
average of $19.4 \%$, and there is no obvious indication of an increasing or decreasing trend for the adjusted $\mathrm{R}^{2}$ as size increases.

Finally, we examine whether the properties of our return model hold for firms with different growth opportunities. We partition the pooled sample into deciles based upon growth opportunities (proxied by consensus analyst forecasts of the long-term growth rate) and run separate regressions for each of the deciles. The qualitative properties predicted by the theoretical model hold for all growth deciles. Again, the adjusted $\mathrm{R}^{2}$ of the model is relatively steady, ranging from $16.4 \%$ to $23.76 \%$, with an average of $20.4 \%$.

\subsection{Incremental importance of the individual factors in explaining returns}

The preceding analysis examines the empirical performance of the return model as a whole. In this subsection, we evaluate the importance of the individual factors in explaining returns. We focus on the unique information conveyed by a single factor (or a subset of factors) beyond that conveyed by other factors of the model, and use "incremental explanatory power" (IEP) to measure this information. Specifically, the IEP of factor $x$ is defined as the $\mathrm{R}^{2}$ of regression model (7) less the $\mathrm{R}^{2}$ of regression model (7) excluding $x .^{22}$ The significance of the IEP can be tested based on the t-statistic for a single factor, or the F-statistic for a group of factors. ${ }^{23}$

In examining the unique information content of a group of factors, we categorize the model's factors into either cash-flow-related (earnings yield, capital investment, and changes in profitability or growth opportunities) or discount-rate-related (change in discount rates). The cash

\footnotetext{
${ }^{22}$ We use the piecewise linear regression (7) to compute IEPs; the results are similar based on linear regression (6). $\mathrm{R}^{2}$ s used in computing IEPs refer to unadjusted $\mathrm{R}^{2} \mathrm{~s}$, consistent with prior studies (e.g., Vuong, 1989; Brown, Lo, and Lys, 1999).

${ }^{23}$ Another measure for the information content of a factor is "relative (or standalone) information content," which captures the total (versus incremental) information conveyed by a factor, irrespective of the information conveyed by other factors. In our return model, the explanatory variables are correlated, as shown in Panel $\mathrm{C}$ of Table 1, so the total information contents of different factors overlap with each
} 
flow factors are further divided into profitability-related (earnings yield and profitability change) and scale-related (capital investment and growth opportunity change) factors.

The results based on the pooled sample are reported in Table 4. We find first that all the factors of the theoretical model play a significant incremental role beyond the other factors of the model, which (again) confirms the empirical validity of all five factors.

[Table 4 about here]

Among the cash flow factors, profitability-related factors (earnings and change in profitability) have an IEP of 9.45\%, whereas scale-related factors (capital investment and growth opportunity shocks) have an IEP of $4.00 \%$. Thus, profitability-related factors provide more incremental information for explaining cross-sectional price movements than do scale changes. Compared with cash-flow-related factors, the change in the discount rate plays a much smaller incremental role in explaining returns, with an IEP of only $2.21 \%$.

In terms of the incremental information conveyed by a single factor, the earnings yield is the most important factor (IEP=2.84\%), followed by the change in profitability (2.31\%), the change in growth opportunities (2.28\%), the change in the discount rate (2.21\%), and the capital investment (1.65\%); all the IEPs are significant at the 1\% level.

We also extend the analysis to subgroups of the pooled sample, partitioned on book-tomarket, size, and growth opportunities, and observe the dominance of cash flow factors over the discount rate change in explaining returns in all subsamples. ${ }^{24}$

Additional (untabulated) analysis shows that the unconditional explanatory powers (also named standalone, or relative, explanatory powers) of individual cash flow factors are much greater than their IEPs presented in Table 4, suggesting that there are considerable overlaps in

other. See Biddle et al. (1995) for a discussion of the incremental and relative information contents of explanatory variables. 
information content among these variables (as confirmed by the correlations in Panel C of Table 1).

\section{Empirical results based on regressions of abnormal returns}

The empirical analysis so far explains total stock returns over a period. One could argue that since accounting fundamentals convey the financial performance of specific firms, they should (largely) relate to firm-specific idiosyncratic risk. ${ }^{25}$ According to established asset pricing theories, in a context in which investors hold diversified portfolios, the expected return of a stock is determined by its systematic risk, whereas the abnormal return is attributable to its idiosyncratic risk. The question here is, to what extent do accounting fundamentals explain abnormal returns? To address this question, we use the following specifications for the abnormal return regressions, analogous to regression equations (6), (7), and (8) above: ${ }^{26}$

$$
\begin{aligned}
& A R_{i t}=\alpha+\beta x_{i t}+\gamma \Delta \hat{q}_{i t}+\delta \Delta \hat{b}_{i t}+\omega \Delta \hat{g}_{i t}+\varphi \Delta \hat{r}_{i t}+e_{i t}, \\
& A R_{i t}=\alpha+\beta x_{i t}+\gamma \Delta \hat{q}_{i t}+\gamma_{M} M \Delta \hat{q}_{i t}+\gamma_{H} H \Delta \hat{q}_{i t} \\
& \quad+\delta \Delta \hat{b}_{i t}+\omega \Delta \hat{g}_{i t}+\omega_{M} M \Delta \hat{g}_{i t}+\omega_{H} H \Delta \hat{g}_{i t}+\varphi \Delta \hat{r}_{i t}+e_{i t},
\end{aligned}
$$

and

$$
A R_{i t}=\alpha+\beta x_{i t}+\lambda \Delta x_{i t}+e_{i t},
$$

where $A R_{i t}$ is the abnormal return of firm $i$ in period $t$, calculated as the portion of the total return that is not explained by the three-factor model of Fama and French (1992, 1993, 1995). All other variables are as defined for (total) return regressions (6), (7), and (8). The results are presented in Table 5.

\footnotetext{
${ }^{24}$ The results from these additional analyses are available upon request.

${ }^{25}$ Strictly speaking, variations in accounting data relate to a firm's total risk; thus, they contain both systematic and idiosyncratic variation.
} 
[Table 5 about here]

Panel A presents the results from the pooled sample. In models (6') and (7'), the coefficients on four of the five factors identified by our return model have the same signs as in the corresponding total return regressions, as reported in Table 2, and they are highly significant as before; the only exception is the coefficient on capital investment, which now becomes significantly negative. In model (8'), the coefficients on earnings and changes in earnings both are positive and significant.

The effect of running regressions of abnormal returns, instead of total returns, is that it first filters out the information in the fundamental factors that overlaps that in the Fama-French factors, leaving only the unique portion of the information in the fundamental factors to explain returns. The changes in estimated coefficients between total return regressions, models (6) and (7) in Table 2, and abnormal return regressions, models (6') and (7') in Table 5, give an indication of how much each of the fundamental factors overlaps with the Fama-French factors. We find that the coefficients on profitability changes and growth opportunity changes do not differ substantially between Table 2 and Table 5, suggesting that the three Fama-French factors (market portfolio, size, and book-to-market) do not effectively anticipate subsequent changes in profitability and in growth opportunities. The coefficients on the earnings yield and discount rate changes decrease substantially in magnitude but are still significant, suggesting that the FamaFrench factors partially anticipate the earnings yield and discount rate changes, but the remaining (unanticipated) portion of the information in these two factors continues to be important in explaining returns. Finally, the effect of capital investment in abnormal return regressions becomes opposite to that in total return regressions. It is well-known that the book-to-market ratio

\footnotetext{
${ }^{26}$ Unlike in the two previous sections, the empirical analysis in this section is more loosely related to our
} 
of equity contains expected growth, so the change in the result for capital investment could be due to the gap between expected growth, as anticipated in the Fama-French factors, and realized growth in the subsequent period. One possible reason for having a negative effect of capital investment on abnormal returns might be that while the market correctly anticipates firms' investment opportunities, firms’ actual investments are suboptimal relative to what are justified by positive NPV projects (this conjecture can be a topic of further research).

Importantly, similar to the results for the total return regressions, the explanatory power of models (6') and (7') is higher than that of earnings-based model (8'); the adjusted $\mathrm{R}^{2} \mathrm{~s}$ are $5.18 \%$ for (6’) and 6.08\% for (7’) versus 3.63\% for (8’). Vuong's Z-tests for comparing the models (6’) and (7') with (8') yield statistics of 6.98 and 8.81, respectively, both significant at the $1 \%$ level, in favor of (6’) and (7’) over (8'). We also observe that the adjusted $\mathrm{R}^{2} \mathrm{~s}$ of (6), (7) and (8’) all become much smaller than those of their counterparts (6), (7), and (8), again suggesting that there are substantial overlaps between the information conveyed by the fundamental factors (as a group) in these models and the information in the three Fama-French factors.

Panel B of Table 5 reports the average coefficients from annual regressions for models (6'), (7’), and (8'), along with the Fama-MacBeth $t$-statistics. The result here generally reinforces that from the pooled sample. The average coefficients on earnings yield, the change in profitability and the change in growth opportunities have the same signs as in total return regressions and are statistically significant. The coefficient on the change in discount rates, while having the same sign as in total return regressions, becomes insignificant. Finally, capital investment on average has little effect on abnormal returns.

theoretical return model. However, developing a formal model of unexpected returns based on accounting data is not a straightforward task, and is beyond the scope of this study. 
As for the total return regressions, the average explanatory power of models (6') and (7’) is higher than that of earnings-based model (8'); the adjusted $\mathrm{R}^{2} \mathrm{~s}$ are $9.55 \%$ for (6') and $10.93 \%$ for (7') versus 5.48\% for (8'). Vuong's Z-test indicates that models (6') and (7') are significantly better than model (8') for all sample years (results are not tabulated but available upon request). Again, the fundamental factors of our theoretical model are better able to explain stock price movements than are the earnings variables used in prior studies.

\section{Summary and concluding remarks}

This study provides theory and empirical evidence that show how accounting fundamentals explain cross-sectional variation in stock returns. According to our model, stock returns are related to the earnings yield, capital investment, and changes in profitability and growth opportunities, as well as to changes in the discount rate. Of these five factors, the first four relate to a firm's cash flows (arising from profitability and scale of operations), and the discount rate affects the pricing of future cash flows.

Empirical analysis based on a comprehensive cross-sectional sample finds that all five identified factors are highly significant and their coefficients have the predicted signs. The qualitative properties of the model are confirmed both in broad samples and in subsamples partitioned by size, book-to-market, and growth opportunities. Most of the qualitative results are similar when we use abnormal returns (as opposed to total returns) as the dependent variable. Compared with existing earnings-based models, our return model is significantly more effective in explaining cross-sectional stock returns.

We find that the information content captured by our model is mainly attributed to the four cash flow factors, with the change in the discount rate playing only a minor role. Among the cash flow factors, profitability-related information (earnings yield and profitability change) is more 
important in explaining price movements than is scale-related information. This result complements similar findings in the finance literature that are inferred from the second-moment behavior of stock returns.

The theoretical and empirical results of this study enhance our understanding of how stock returns relate to accounting fundamentals. Compared with models developed in the finance literature that are based on common risk factors (which typically have very low $\mathrm{R}^{2} \mathrm{~s}$ in explaining firm-level returns), our accounting-based model holds greater promise in explaining crosssectional price movements. This suggests that it may be more fruitful for investors to search for information on fundamental characteristics of firms' operations than to exploit common-factorbased anomalies. In the investment world, there has been growing interest in designing trading strategies that rely on accounting fundamentals. Our model provides insights into which accounting measures of underlying operations are "core” factors for explaining value and returns.

Our return model can also serve as a benchmark for empirical research on valuation and financial reporting. For example, the model can potentially be applied to earnings response research to predict or explain how the response coefficient should vary with a firm's profitability or growth opportunities. ${ }^{27}$

\footnotetext{
${ }^{27}$ As Kothari (2001) points out, a valuation model underlies earnings response coefficient (ERC) estimation. Note that when applied to a short return window, our model's structure can be simplified (because some of the factors, such as the change in growth opportunities and the change in the discount rate, would be approximately zero).
} 


\section{References}

Ali, A., Zarowin, P., 1992. The role of earnings levels in annual earnings-returns studies. Journal of Accounting Research 30, 286-296.

Berk, J., Green, R., Naik, V., 1999. Optimal investment, growth options, and security returns. Journal of Finance 54, 1553-1607.

Berger, P., Ofek, E., Swary, I., 1996. Investor valuation of the abandonment option. Journal of Financial Economics 42, 1-31.

Biddle, G., Seow, G., Siedel, A., 1995. Relative versus incremental information content. Contemporary Accounting Research 12, 1-23.

Biddle, G., Chen, P., Zhang, G., 2001. When capital follows profitability: Nonlinear residual income dynamics. Review of Accounting Studies 6, 229-265.

Brennan, M., Schwartz, E., 1985. Evaluating natural resources investments. Journal of Business 58, 135-157.

Brown, S., Lo, K., Lys T., 1999. Use of $\mathrm{R}^{2}$ in accounting research: measuring changes in value relevance over the last four decades. Journal of Accounting and Economics 28, 83-115.

Burgstahler, D., Dichev, I., 1997. Earnings, adaptation, and equity value. The Accounting Review 73, 187-215.

Chan, L., Karceski, J., Lakonishok, J., 2002. The level and persistence of growth rates. Journal of Finance 58, 643-684.

Copeland, T., Dolgoff, A., Moel, A., 2004. The role of expectations in explaining the crosssection of stock returns. Review of Accounting Studies 9, 149-188.

Easton, P., Harris, T., 1991. Earnings as an explanatory variable for returns. Journal of Accounting Research 29, 19-36.

Ely, K., Waymire, G., 1999. Accounting standard-setting organizations and earnings relevance: Longitudinal evidence from NYSE common stocks, 1927-1993. Journal of Accounting Research 37, 293-318.

Fama, E., 1970. Efficient capital markets: a review of theory and empirical work. Journal of Finance 25, 383-417.

Fama, E., French, K., 1992. The cross-section of expected stock returns. Journal of Finance 47, 427-466.

Fama, E., French, K., 1993. Common risk factors in the returns on stocks and bonds. Journal of Financial Economics 33, 3-56. 
Fama, E., French, K., 1995. Size and book-to-market factors in earnings and returns. Journal of Finance 50, 131-155.

Fama, E., French, K., 2000. Forecasting profitability and earnings. Journal of Business 73. 161-175.

Fama, E., MacBeth, J., 1973. Risk, return and equilibrium: Empirical test. Journal of Political Economy, 607-636.

Feltham, G., Ohlson, J., 1995. Valuation and clean surplus accounting for operating and financing activities. Contemporary Accounting Research 11, 689-731.

Feltham, G., Ohlson, J., 1996. Uncertain resolution and the theory of depreciation measurement. Journal of Accounting Research 34, 209-234.

Financial Accounting Standards Board, 1978. Statement of financial accounting concepts No.1: Objectives of financial reporting by business enterprises. FASB, Stamford, CT.

Financial Accounting Standards Board, 1978. Statement of financial accounting concepts No.5: Recognition and measurement in financial statements of business enterprises. FASB, Stamford, CT.

Francis, J., Schipper, K., 1999. Have financial statements lost their relevance? Journal of Accounting Research 37, 319-352.

Kothari, S.P., 2001. Capital markets research in accounting. Journal of Accounting and Economics 31, 105-231.

Lev, B., 1989. On the usefulness of earnings and earnings research: Lessons and directions from two decades of empirical research. Journal of Accounting Research 27, 153-192.

Lev, B., Zarowin, P., 1999. The boundaries of financial reporting and how to extend them. Journal of Accounting Research 37, 353-385.

Liu, J., Thomas, J., 2000. Stock returns and accounting earnings. Journal of Accounting Research 36, 71-101.

Lo, K., Lys, T., 2000. The Ohlson model: Contribution to valuation theory, limitations, and empirical applications. Journal of Accounting, Auditing and Finance 15, 337-367.

Miller, M., Modigliani, F., 1961. Dividend policy, growth, and the valuation of shares. Journal of Business 34, 411-433.

Myers, S., 1977. Determinants of corporate borrowing. Journal of financial economics 5, 147175. 
Ohlson, J., 1995. Earnings, book values, and dividends in equity valuation. Contemporary Accounting Research 11, 661-687.

Patel, J., 1989. Discussion of 'On the usefulness of earnings and earnings research: Lessons and directions from two decades of empirical research.' Journal of Accounting Research 27, 193-201.

Vuong, Q., 1989. Likelihood ratio tests for model selection and non-nested hypotheses.

Econometrica 57, 307-333.

Zhang, G., 2000. Accounting information, capital investment decisions, and equity valuation: Theory and empirical implications. Journal of Accounting Research 38, 271-295. 
Table 1. Descriptive statistics of the sample

This table reports the distributional statistics of the following variables for the pooled sample (Panel A) and for annual samples (Panel B), and the correlations between the variables (Panel C). The stock return $\left(R_{t}\right)$ is the return from two days after the prior year's earnings announcement to one day after the current year's earnings announcement; earnings yield $\left(x_{t}\right)$ is earnings $\left(X_{t}\right)$ divided by beginning-ofperiod market value of equity $\left(V_{t-1}\right)$; profitability change $\left(\Delta q_{i t}\right)$ is year $t$ profitability $q_{t}$ minus year $t-1$ profitability $q_{t-1}$, where $q_{t}=X_{t} / B_{t-1}$; the adjusted profitability change $\left(\Delta \hat{q}_{i t}\right)$ is the profitability change multiplied by the beginning-of-period book-to-market ratio $\left(B_{i t-1} / V_{i t-1}\right)$; capital investment $\left(\Delta B_{i t} / B_{i t-1}\right)$ is the change in the book value of equity relative to the prior year scaled by beginning-of-period book value; the adjusted capital investment $\left(\Delta \hat{b}_{i t}\right)$ is capital investment multiplied by $\left(1-B_{i t-1} / V_{i t-1}\right)$; growth opportunity change ( $\left.\Delta g_{i t}\right)$ is the change in the median analyst forecast of the long-term growth rate following the current year earnings announcement relative to that of the prior year; the adjusted growth opportunity change $\left(\Delta \hat{g}_{i t}\right)$ is growth opportunity change multiplied by $B_{i t-1} / V_{i t-l}$; discount rate change $\left(\Delta r_{i t}\right)$ is the change of the 10-year U.S. Treasury bond yield over the return period; and the adjusted discount rate change ( $\left.\Delta \hat{r}_{i t}\right)$ is the discount rate change multiplied by $B_{i t-1} / V_{i t-1}$. The pooled sample consists of 27,897 firm-year observations for $1983-2001$ (19 years).

Panel A: Descriptive statistics of the pooled sample

\begin{tabular}{lrrrrrrr}
\hline Variable & Mean & Median & $\begin{array}{r}\text { Std } \\
\text { dev }\end{array}$ & Min. & $\begin{array}{r}\text { 1st } \\
\text { quartile }\end{array}$ & $\begin{array}{r}\text { 3rd } \\
\text { quartile }\end{array}$ & Max \\
\hline Stock return $\left(R_{i t}\right)$ & 0.15 & 0.10 & 0.43 & -0.78 & -0.12 & 0.35 & 2.73 \\
Earning yield $\left(x_{i t}\right)$ & 0.06 & 0.07 & 0.08 & -1.39 & 0.04 & 0.09 & 0.49 \\
Profitability change $\left(\Delta q_{i t}\right)(\%)$ & -1.55 & -0.01 & 14.53 & -143.20 & -5.61 & 3.14 & 149.47 \\
Adjusted profitability change $\left(\Delta \hat{q}_{i t}\right)(\%)$ & -0.90 & -0.18 & 7.87 & -54.42 & -3.67 & 1.54 & 39.91 \\
Capital investment $\left(\Delta B_{i t} / B_{i t-1}\right)$ & 0.13 & 0.10 & 0.27 & -0.91 & 0.02 & 0.19 & 4.40 \\
Adjusted capital investment $\left(\Delta \hat{b}_{i t}\right)$ & 0.08 & 0.03 & 0.18 & 0.38 & 0.01 & 0.11 & 1.65 \\
Growth opportunity change $\left(\Delta g_{i t}\right)(\%)$ & -0.53 & -0.09 & 3.74 & -55.00 & -1.60 & 0.74 & 47.00 \\
Adjusted growth opportunity change $\left(\Delta \hat{g}_{i t}\right)$ & -0.24 & -0.03 & 2.11 & -12.78 & -0.75 & 0.32 & 13.42 \\
Discount rate change $\left(\Delta r_{i t}\right)(\%)$ & -0.29 & -0.51 & 1.18 & -4.34 & -1.04 & 0.61 & 3.18 \\
Adjusted discount rate change $\left(\Delta \hat{r}_{i t}\right)$ & -0.19 & -0.20 & 0.80 & -3.50 & -0.55 & 0.26 & 2.30 \\
B/M ratio $\left(B_{i t-1} / V_{i t-1}\right)$ & 0.59 & 0.53 & 0.35 & 0.01 & 0.34 & 0.76 & 4.43 \\
\hline
\end{tabular}


Table 1 Continued

Panel B: Descriptive statistics of annual samples

\begin{tabular}{|c|c|c|c|c|c|c|c|c|c|c|}
\hline \multirow[t]{2}{*}{ Year } & \multirow[t]{2}{*}{ Obs } & \multicolumn{3}{|c|}{ Stock return $\left(R_{i t}\right)$} & \multicolumn{3}{|c|}{ Earnings yield $\left(x_{i t}\right)$} & \multicolumn{3}{|c|}{$\begin{array}{c}\text { Profitability change }\left(\Delta q_{i t}\right) \\
(\%)\end{array}$} \\
\hline & & Mean & Median & Std dev & Mean & Median & Std dev & Mean & Median & Std dev \\
\hline 1983 & 921 & 0.22 & 0.17 & 0.35 & 0.10 & 0.10 & 0.10 & -0.21 & 0.33 & 8.40 \\
\hline 1984 & 990 & 0.13 & 0.14 & 0.27 & 0.09 & 0.09 & 0.09 & -0.09 & 0.22 & 6.34 \\
\hline 1985 & 1,006 & 0.25 & 0.23 & 0.33 & 0.08 & 0.09 & 0.09 & -1.89 & -0.74 & 8.12 \\
\hline 1986 & 1,226 & 0.24 & 0.23 & 0.34 & 0.06 & 0.07 & 0.09 & -1.19 & -0.33 & 7.74 \\
\hline 1987 & 1,132 & -0.06 & -0.09 & 0.29 & 0.06 & 0.07 & 0.08 & -0.18 & -0.04 & 7.73 \\
\hline 1988 & 1,131 & 0.17 & 0.14 & 0.31 & 0.08 & 0.09 & 0.08 & 0.66 & 0.47 & 7.96 \\
\hline 1989 & 1,225 & 0.12 & 0.11 & 0.33 & 0.07 & 0.08 & 0.08 & -1.42 & -0.48 & 7.81 \\
\hline 1990 & 1,295 & 0.01 & -0.01 & 0.37 & 0.05 & 0.07 & 0.09 & -2.21 & -0.78 & 8.67 \\
\hline 1991 & 1,356 & 0.35 & 0.26 & 0.49 & 0.06 & 0.07 & 0.10 & -2.14 & -0.90 & 9.24 \\
\hline 1992 & 1,436 & 0.15 & 0.13 & 0.38 & 0.05 & 0.06 & 0.09 & -0.25 & -0.01 & 7.81 \\
\hline 1993 & 1,487 & 0.17 & 0.10 & 0.39 & 0.05 & 0.06 & 0.08 & -0.25 & 0.12 & 7.46 \\
\hline 1994 & 1,525 & 0.02 & 0.00 & 0.31 & 0.06 & 0.06 & 0.06 & 0.15 & 0.09 & 6.62 \\
\hline 1995 & 1,632 & 0.28 & 0.24 & 0.44 & 0.06 & 0.07 & 0.08 & -0.56 & 0.05 & 7.78 \\
\hline 1996 & 1,833 & 0.18 & 0.15 & 0.41 & 0.05 & 0.06 & 0.07 & -0.80 & -0.24 & 7.39 \\
\hline 1997 & 2,023 & 0.28 & 0.24 & 0.43 & 0.05 & 0.06 & 0.07 & -0.35 & 0.02 & 6.75 \\
\hline 1998 & 2,102 & -0.04 & -0.08 & 0.42 & 0.03 & 0.05 & 0.07 & -1.64 & -0.42 & 7.27 \\
\hline 1999 & 2,030 & 0.11 & -0.06 & 0.61 & 0.05 & 0.05 & 0.08 & -0.35 & -0.02 & 8.02 \\
\hline 2000 & 1,855 & 0.17 & 0.11 & 0.55 & 0.05 & 0.06 & 0.09 & -0.90 & -0.05 & 8.30 \\
\hline 2001 & 1,692 & 0.10 & 0.06 & 0.46 & 0.03 & 0.04 & 0.10 & -3.07 & -1.29 & 9.02 \\
\hline
\end{tabular}


Table 1 Continued

Panel B. Descriptive statistics of annual samples (continued)

\begin{tabular}{|c|c|c|c|c|c|c|c|c|c|c|c|}
\hline \multicolumn{3}{|c|}{$\begin{array}{l}\text { Capital investment } \\
\qquad\left(\Delta B_{i t} / B_{i t-1}\right)\end{array}$} & \multicolumn{3}{|c|}{$\begin{array}{l}\text { Growth opportunity change } \\
\qquad\left(\Delta g_{i t}\right)(\%)\end{array}$} & \multicolumn{3}{|c|}{$\begin{array}{c}\text { Discount rate change }\left(\Delta r_{i t}\right) \\
(\%)\end{array}$} & \multicolumn{3}{|c|}{ Beginning B/M } \\
\hline Mean & Median & Std dev & Mean & Median & Std dev & Mean & Median & Std dev & Mean & Median & Std dev \\
\hline 0.14 & 0.10 & 0.22 & 0.37 & 0.00 & 3.68 & 1.09 & 1.14 & 0.82 & 0.87 & 0.86 & 0.41 \\
\hline 0.08 & 0.09 & 0.14 & -0.63 & -0.40 & 3.41 & -0.34 & -0.33 & 0.76 & 0.76 & 0.73 & 0.34 \\
\hline 0.10 & 0.09 & 0.22 & -1.12 & -0.78 & 3.84 & -2.63 & -2.68 & 0.56 & 0.74 & 0.71 & 0.30 \\
\hline 0.12 & 0.10 & 0.24 & -1.06 & -0.55 & 3.86 & -1.51 & -1.45 & 1.07 & 0.64 & 0.63 & 0.29 \\
\hline 0.11 & 0.09 & 0.22 & -0.56 & -0.33 & 3.48 & 1.24 & 1.12 & 0.43 & 0.59 & 0.58 & 0.28 \\
\hline 0.10 & 0.10 & 0.19 & -0.62 & -0.14 & 3.18 & 0.49 & 0.50 & 0.56 & 0.68 & 0.63 & 0.36 \\
\hline 0.11 & 0.09 & 0.21 & -0.52 & -0.17 & 3.41 & -0.73 & -0.77 & 0.36 & 0.65 & 0.61 & 0.31 \\
\hline 0.09 & 0.08 & 0.20 & -0.63 & -0.31 & 3.45 & -0.22 & -0.36 & 0.45 & 0.61 & 0.58 & 0.31 \\
\hline 0.13 & 0.08 & 0.28 & -0.47 & -0.10 & 2.98 & -0.80 & -0.82 & 0.28 & 0.74 & 0.66 & 0.47 \\
\hline 0.11 & 0.08 & 0.28 & -0.28 & 0.00 & 2.97 & -0.93 & -1.08 & 0.39 & 0.60 & 0.55 & 0.35 \\
\hline 0.14 & 0.09 & 0.28 & -0.21 & 0.00 & 3.29 & -0.37 & -0.51 & 0.70 & 0.55 & 0.52 & 0.30 \\
\hline 0.13 & 0.10 & 0.23 & -0.38 & 0.00 & 3.27 & 1.45 & 1.56 & 0.83 & 0.50 & 0.47 & 0.25 \\
\hline 0.19 & 0.12 & 0.33 & -0.25 & 0.00 & 3.86 & -1.51 & -1.66 & 0.71 & 0.55 & 0.51 & 0.29 \\
\hline 0.17 & 0.11 & 0.30 & -0.15 & 0.00 & 3.80 & 0.56 & 0.61 & 0.34 & 0.51 & 0.46 & 0.29 \\
\hline 0.17 & 0.12 & 0.30 & -0.31 & 0.00 & 4.04 & -0.87 & -0.88 & 0.24 & 0.50 & 0.46 & 0.28 \\
\hline 0.14 & 0.10 & 0.31 & -0.84 & -0.17 & 3.86 & -0.69 & -0.76 & 0.34 & 0.44 & 0.39 & 0.25 \\
\hline 0.14 & 0.08 & 0.32 & -0.67 & -0.12 & 3.82 & 1.42 & 1.52 & 0.46 & 0.50 & 0.45 & 0.31 \\
\hline 0.16 & 0.10 & 0.32 & -0.29 & 0.00 & 4.30 & -1.20 & -1.42 & 0.47 & 0.56 & 0.47 & 0.40 \\
\hline 0.12 & 0.08 & 0.28 & -1.45 & -0.55 & 4.76 & -0.24 & -0.12 & 0.37 & 0.57 & 0.46 & 0.46 \\
\hline
\end{tabular}


Table 1 Continued

Panel C: Correlation matrix

\begin{tabular}{lccccc}
\hline Variable & $R_{i t}$ & $x_{i t}$ & $\Delta q_{i t}$ & $\Delta B_{i t} / B_{i t-1}$ & $\Delta g_{i t}$ \\
\hline Earning yield $\left(x_{i t}\right)$ & $0.29^{* *}$ & & & & \\
Profitability change $\left(\Delta q_{i t}\right)$ & $0.29^{* *}$ & $0.45^{* *}$ & & & \\
Capital investment $\left(\Delta B_{i t} / B_{i t-1}\right)$ & $0.24^{* *}$ & $0.33^{* *}$ & $0.26^{* *}$ & & \\
Growth opportunity change $\left(\Delta g_{i t}\right)$ & $0.23^{* *}$ & $0.09^{* *}$ & $0.16^{* *}$ & $0.07^{* *}$ & \\
Discount rate change $\left(\Delta r_{i t}\right)$ & $-0.13^{* *}$ & 0.00 & $0.05^{* *}$ & 0.00 & $0.02^{* *}$ \\
\hline
\end{tabular}

** indicates statistical significance at the $1 \%$ level. 
Table 2. Regression results from the pooled sample

This table reports the results from the pooled sample of the following regression models:

$$
\begin{aligned}
& \text { Model (6): } R_{i t}=\alpha+\beta x_{i t}+\gamma \Delta \hat{q}_{i t}+\delta \Delta \hat{b}_{i t}+\omega \Delta \hat{g}_{i t}+\varphi \Delta \hat{r}_{i t}+e_{i t} ; \\
& \text { Model (7): } R_{i t}=\alpha+\beta x_{i t}+\gamma \Delta \hat{q}_{i t}+\gamma_{M} M \Delta \hat{q}_{i t}+\gamma_{H} H \Delta \hat{q}_{i t}+\delta \Delta \hat{b}_{i t}+\omega \Delta \hat{g}_{i t}+\omega_{M} M \Delta \hat{g}_{i t}+\omega_{H} H \Delta \hat{g}_{i t}+\varphi \Delta \hat{r}_{i t}+e_{i t} ; \\
& \text { Model (8): } R_{i t}=\alpha+\beta x_{i t}+\lambda \Delta x_{i t}+e_{i t} ; \\
& \text { Model (9): } R_{i t}=\alpha+\beta x_{i t}+\lambda \Delta \hat{q}_{i t}+e_{i t} .
\end{aligned}
$$

$R_{i t}$ is the annual stock return, measured from two days after the earnings announcement for year $t-1$ to one day after the earnings announcement for year $t ; x_{i t}=X_{i t} / V_{i t-1}$ is earnings divided by beginning-of-period market value of equity; $\Delta x_{i t}=\left(X_{i t}-X_{i t-1}\right) / V_{i t-1} ; \Delta \hat{q}_{i t}=\left(q_{i t}-\right.$ $\left.q_{i t-1}\right) B_{i t-1} / V_{i t-1}$ is the change in profitability multiplied by the beginning-of-period book-to-market ratio, with profitability defined as $q_{i t}=$ $X_{i t} / B_{i t-1} ; \Delta b_{i t}=\left(B_{i t}-B_{i t-1}\right) / B_{i t-1}\left(1-B_{i t-1} / V_{i t-1}\right)$ is capital investment multiplied by one minus the beginning-of-period book-to-market ratio; $\Delta \hat{g}_{i t}=\left(g_{i t}-g_{i t-1}\right) B_{i t-1} / V_{i t-1}$ is the change in growth opportunities multiplied by the beginning-of-period book-to-market ratio; $\Delta \hat{r}_{i t}=\left(r_{t}-r_{t-}\right.$ 1) $B_{i t-1} / V_{i t-1}$ is the change in the discount rate in year $t$ multiplied by the beginning-of-period book-to-market ratio; and $M$ and $H$ are dummy variables for the middle- and high-third profitability ranges of the sample, respectively. ${ }^{*}$ and ${ }^{* *}$ indicate coefficients significantly different from zero at the $5 \%$ and $1 \%$ levels, respectively. 
Table 2 Continued

\begin{tabular}{|c|c|c|c|c|c|c|c|c|c|}
\hline \multirow{2}{*}{ Variable } & \multirow{2}{*}{$\begin{array}{l}\text { Predicted } \\
\text { Value/sign }\end{array}$} & \multicolumn{2}{|c|}{ Model (6) } & \multicolumn{2}{|c|}{ Model (7) } & \multicolumn{2}{|c|}{ Model (8) } & \multicolumn{2}{|c|}{ Model (9) } \\
\hline & & \multicolumn{2}{|c|}{ Estimate (t-value) } & \multicolumn{2}{|c|}{ Estimate (t-value) } & \multicolumn{2}{|c|}{ Estimate (t-value) } & \multicolumn{2}{|c|}{ Estimate (t-value) } \\
\hline Intercept & $+/-$ & $0.07^{* *}$ & (19.44) & $0.05^{* *}$ & $(13.43)$ & $0.08^{* *}$ & (25.52) & $0.10^{* *}$ & (29.63) \\
\hline$x$ & +1 & $0.97^{* *}$, a & $(27.71)$ & $1.09^{* *, \mathrm{~b}}$ & $(30.79)$ & $1.21^{* *, \mathrm{~b}}$ & $(37.26)$ & $1.02^{* *, \mathrm{a}}$ & (28.28) \\
\hline$\Delta x$ & + & & & & & $0.64^{* *}$ & (21.57) & & \\
\hline$\Delta \hat{q}$ & + & $0.76^{* *}$ & (20.34) & $0.32^{* *}$ & $(7.37)$ & & & $0.89^{* *}$ & (23.10) \\
\hline$M \Delta \hat{q}$ & + & & & $1.30^{* *}$ & (13.54) & & & & \\
\hline$H \Delta \hat{q}$ & + & & & $1.35^{* *}$ & $(15.30)$ & & & & \\
\hline$\Delta \hat{b}$ & +1 & $0.31^{* *, \mathrm{~b}}$ & (23.38) & $0.31^{* *, \mathrm{~b}}$ & $(23.35)$ & & & & \\
\hline$\Delta \hat{g}$ & + & $2.97^{* *}$ & (26.17) & $2.49^{* *}$ & $(17.54)$ & & & & \\
\hline$M \Delta \hat{g}$ & + & & & 0.20 & $(0.74)$ & & & & \\
\hline$H \Delta \hat{g}$ & + & & & $2.85^{* *}$ & $(8.61)$ & & & & \\
\hline$\Delta \hat{r}$ & - & $-0.08^{* *}$ & $(-27.52)$ & $-0.08^{* *}$ & $(-27.11)$ & & & & \\
\hline \multicolumn{2}{|c|}{ Adj. R²(\%) } & & $6.01^{\mathrm{c}, \mathrm{d}}$ & \multicolumn{2}{|c|}{$17.40^{\mathrm{c}, \mathrm{d}}$} & \multicolumn{2}{|c|}{10.01} & \multicolumn{2}{|c|}{10.23} \\
\hline
\end{tabular}

${ }^{\text {a }}$ The coefficient is not significantly different from the predicted value of one at the $5 \%$ level.

${ }^{\mathrm{b}}$ The coefficient is significantly different from the predicted value of one at the $5 \%$ level.

${ }^{\mathrm{c}}$ Vuong's Z-tests for comparing models (6) and (7) with (8) yield statistics of 14.53 and 16.17, respectively, both significant at the $1 \%$ level, in favor of (6) and (7) over (8).

${ }^{\mathrm{d}}$ Vuong's Z-tests for comparing models (6) and (7) with (9) yield statistics of 14.26 and 15.94, respectively, both significant at the $1 \%$ level, in favor of (6) and (7) over (9). 
Table 3. Regression results on annual samples

This table reports the results from the annual samples of the following regression models:

$$
\begin{aligned}
& \text { Model (6): } R_{i t}=\alpha+\beta x_{i t}+\gamma \Delta \hat{q}_{i t}+\delta \Delta \hat{b}_{i t}+\omega \Delta \hat{g}_{i t}+\varphi \Delta \hat{r}_{i t}+e_{i t} ; \\
& \text { Model (7): } R_{i t}=\alpha+\beta x_{i t}+\gamma \Delta \hat{q}_{i t}+\gamma_{M} M \Delta \hat{q}_{i t}+\gamma_{H} H \Delta \hat{q}_{i t}+\delta \Delta \hat{b}_{i t}+\omega \Delta \hat{g}_{i t}+\omega_{M} M \Delta \hat{g}_{i t}+\omega_{H} H \Delta \hat{g}_{i t}+\varphi \Delta \hat{r}_{i t}+e_{i t} ; \\
& \text { Model (8): } R_{i t}=\alpha+\beta x_{i t}+\lambda \Delta x_{i t}+e_{i t} .
\end{aligned}
$$

$R_{i t}$ is the annual stock return, measured from two days after the earnings announcement for year $t-1$ to one day after the earnings announcement for year $t ; x_{i t}=X_{i t} / V_{i t-1}$ is earnings divided by beginning-of-period market value of equity; $\Delta x_{i t}=\left(X_{i t} X_{i t-1}\right) V_{i t-1} ; \Delta \hat{q}_{i t}=\left(q_{i t}-q_{i t-}\right.$ 1) $B_{i t-1} / V_{i t-1}$ is the change in profitability multiplied by the beginning-of-period book-to-market ratio, with profitability defined as $q_{i t}=X_{i t}$ $/ B_{i t-1} ; \Delta b_{i t}=\left(B_{i t}-B_{i t-1}\right) / B_{i t-1}\left(1-B_{i t-1} / V_{i t-1}\right)$ is capital investment multiplied by one minus the beginning-of-period book-to-market ratio; $\Delta \hat{g}_{i t}=$ $\left(g_{i t}-g_{i t-1}\right) B_{i t-1} / V_{i t-1}$ is the change in growth opportunities multiplied by the beginning-of-period book-to-market ratio; $\Delta \hat{r}_{i t}=\left(r_{t}-r_{t-1}\right) B_{i t-1} / V_{i t-1}$ is the change in the discount rate in year $t$ multiplied by the beginning-of-period book-to-market ratio; and $M$ and $H$ are dummy variables for the middle- and high-third profitability ranges of the sample, respectively.

The annual results are summarized by average coefficient estimates, with significance indicated by the Fama-MacBeth $t$-statistic. ${ }^{*}$ and ${ }^{* *}$ indicate coefficients significantly different from zero at the $5 \%$ and $1 \%$ levels, respectively. 
Table 3 Continued

Panel A. Linear regression model (6)

\begin{tabular}{|c|c|c|c|c|c|c|c|c|}
\hline Year & Obs. & $\begin{array}{l}\text { Inter- } \\
\text { cept }\end{array}$ & $x$ & $\Delta \hat{q}$ & $\Delta \hat{b}$ & $\Delta \hat{g}$ & $\Delta \hat{r}$ & $\begin{array}{l}\text { Adj. } \\
\mathrm{R}^{2}(\%)\end{array}$ \\
\hline 1983 & 921 & $0.24^{* *}$ & $1.09^{* *, \mathrm{~b}}$ & 0.05 & $-0.20^{\mathrm{c}}$ & $2.27^{* *}$ & $-0.15^{* *}$ & 20.79 \\
\hline 1984 & 990 & $-0.05^{* *}$ & $1.63^{* *, \mathrm{c}}$ & 0.14 & $0.23^{* *, c}$ & $1.59^{* *}$ & $-0.11^{* *}$ & 32.92 \\
\hline 1985 & 1,006 & $0.14^{* *}$ & $1.24^{* *, \mathrm{~b}}$ & $0.34^{*}$ & $0.27^{* *, \mathrm{c}}$ & $3.01^{* *}$ & -0.01 & 24.88 \\
\hline 1986 & 1,226 & $0.18^{* *}$ & $0.85^{* *, \mathrm{~b}}$ & $0.57^{* *}$ & $0.24^{* *, \mathrm{c}}$ & $2.33^{* *}$ & -0.01 & 17.04 \\
\hline 1987 & 1,132 & $-0.17^{* *}$ & $0.43^{* *, c}$ & $0.62^{* *}$ & $0.25^{* *, \mathrm{c}}$ & 0.35 & 0.10 & 8.94 \\
\hline 1988 & 1,131 & $0.08^{* *}$ & $0.85^{* *, \mathrm{~b}}$ & $0.54^{* *}$ & $0.15^{*, \mathrm{c}}$ & $2.28^{* *}$ & 0.05 & 14.31 \\
\hline 1989 & 1,225 & $0.08^{* *}$ & $0.55^{* *, \mathrm{c}}$ & $1.02^{* *}$ & $0.36^{* *, \mathrm{c}}$ & $3.99^{* *}$ & -0.01 & 23.95 \\
\hline 1990 & 1,295 & $-0.07^{* *}$ & $0.55^{* *, \mathrm{c}}$ & $1.04^{* *}$ & $0.83^{* *, \mathrm{c}}$ & $1.69^{* *}$ & $-0.28^{* *}$ & 27.73 \\
\hline 1991 & 1,356 & 0.03 & $1.42^{* *, \mathrm{c}}$ & $0.73^{* *}$ & $0.63^{* *, \mathrm{c}}$ & $2.78^{* *}$ & $-0.36^{* *}$ & 25.22 \\
\hline 1992 & 1,436 & 0.01 & $0.90^{* *, \mathrm{~b}}$ & $1.21^{* *}$ & $0.27^{* *, \mathrm{c}}$ & $3.37^{* *}$ & $-0.15^{* *}$ & 23.61 \\
\hline 1993 & 1,487 & $0.12^{* *}$ & $0.04^{\mathrm{c}}$ & $1.20^{* *}$ & $0.50^{* *, \mathrm{c}}$ & $3.72^{* *}$ & $-0.08^{* *}$ & 18.82 \\
\hline 1994 & 1,525 & 0.00 & $1.05^{* *, \mathrm{~b}}$ & $0.73^{* *}$ & $0.11^{*, \mathrm{c}}$ & $3.54^{* *}$ & $-0.06^{* *}$ & 16.15 \\
\hline 1995 & 1,632 & $0.16^{* *}$ & $0.98^{* *, \mathrm{~b}}$ & $0.97^{* *}$ & $0.45^{* *, \mathrm{c}}$ & $3.57^{* *}$ & $-0.03^{*}$ & 20.84 \\
\hline 1996 & 1,833 & 0.02 & $1.83^{* *, \mathrm{c}}$ & $0.45^{* *}$ & $0.26^{* *, \mathrm{c}}$ & $3.55^{* *}$ & 0.12 & 20.22 \\
\hline 1997 & 2,023 & $0.07^{* *}$ & $1.80^{* *, \mathrm{c}}$ & $0.73^{* *}$ & $0.24^{* *, \mathrm{c}}$ & $3.84^{* *}$ & $-0.21^{* *}$ & 22.56 \\
\hline 1998 & 2,102 & -0.03 & $0.28^{*, \mathrm{c}}$ & $1.20^{* *}$ & $0.33^{* *, \mathrm{c}}$ & $4.24^{* *}$ & 0.05 & 14.32 \\
\hline 1999 & 2,030 & $0.06^{*}$ & $-1.07^{\mathrm{c}}$ & $1.87^{* *}$ & $0.66^{* *, \mathrm{c}}$ & $3.87^{* *}$ & 0.08 & 12.44 \\
\hline 2000 & 1,855 & -0.04 & $1.66^{* *, \mathrm{c}}$ & $0.58^{* *}$ & $0.29^{* *, \mathrm{c}}$ & $3.68^{* *}$ & $-0.16^{* *}$ & 15.15 \\
\hline 2001 & 1,692 & $0.08^{* *}$ & $1.09^{* *, \mathrm{~b}}$ & $0.63^{* *}$ & $-0.01^{\mathrm{c}}$ & $1.97^{* *}$ & $-0.15^{* *}$ & 13.51 \\
\hline \multirow{2}{*}{\multicolumn{2}{|c|}{$\begin{array}{l}\text { Average a }^{\text {a }} \\
\text { 1983-2001 }\end{array}$}} & $0.05^{*}$ & $0.90^{* *, b}$ & $0.77^{* *}$ & $0.31^{* *, c}$ & $2.93^{* *}$ & $-0.07^{*}$ & \multirow{3}{*}{19.65} \\
\hline & & (2.19) & $(5.65)$ & (7.80) & (5.71) & (12.36) & $(-2.42)$ & \\
\hline \multicolumn{2}{|c|}{$\begin{array}{l}\text { Predicted } \\
\text { value/sign }\end{array}$} & $+/-$ & +1 & + & +1 & + & - & \\
\hline
\end{tabular}

${ }^{a}$ Numbers in parentheses are $t$-values based on the Fama-MacBeth approach.

${ }^{\mathrm{b}}$ The coefficient is not significantly different from the predicted value of one at the $5 \%$ level.

${ }^{c}$ The coefficient is significantly different from the predicted value of one at the $5 \%$ level. 
Table 3 Continued

Panel B. Piecewise linear regression model (7)

\begin{tabular}{|c|c|c|c|c|c|c|c|c|c|c|c|}
\hline Year & $\begin{array}{l}\text { Inter- } \\
\text { cept }\end{array}$ & $x$ & $\Delta \hat{q}$ & $M \Delta \hat{q}$ & $H \Delta \hat{q}$ & $\Delta \hat{b}$ & $\Delta \hat{g}$ & $M \Delta \hat{g}$ & $H \Delta \hat{g}$ & $\Delta \hat{r}$ & $\begin{array}{c}\text { Adj. } \\
\mathrm{R}^{2}(\%)\end{array}$ \\
\hline 1983 & $0.22^{* *}$ & $1.17^{* *}, \mathrm{~b}$ & -0.55 & $1.41^{* *}$ & $1.54^{* *}$ & $-0.22^{\mathrm{C}}$ & $2.29^{* *}$ & -0.82 & 0.96 & $-0.15^{* *}$ & 23.72 \\
\hline 1984 & $-0.05^{* *}$ & $1.64^{* *, \mathrm{c}}$ & -0.34 & 0.08 & $1.49^{* *}$ & $0.23^{* *, c}$ & $1.12^{* *}$ & 0.51 & $1.47^{*}$ & $-0.11^{* *}$ & 34.96 \\
\hline 1985 & $0.14^{* *}$ & $1.33^{* *, \mathrm{~b}}$ & 0.07 & $1.07^{* *}$ & $1.41^{* *}$ & $0.24^{* *, \mathrm{c}}$ & $2.56^{* *}$ & $1.60^{*}$ & -1.36 & 0.00 & 27.37 \\
\hline 1986 & $0.18^{* *}$ & $0.93^{* *, b}$ & $0.39^{* *}$ & 0.54 & $0.65^{*}$ & $0.25^{* *, \mathrm{c}}$ & $1.86^{* *}$ & 0.75 & $2.45^{*}$ & -0.01 & 18.07 \\
\hline 1987 & $-0.18^{* *}$ & $0.50^{* *, c}$ & $0.38^{* *}$ & $0.61^{*}$ & $0.78^{* *}$ & $0.24^{* *, \mathrm{c}}$ & -0.12 & 0.96 & $2.02^{*}$ & 0.09 & 10.43 \\
\hline 1988 & $0.07^{* *}$ & $0.83^{* *, b}$ & 0.15 & $0.64^{*}$ & $1.26^{* *}$ & $0.16^{*, \mathrm{c}}$ & $2.03^{* *}$ & -0.78 & $2.65^{* *}$ & 0.05 & 17.22 \\
\hline 1989 & $0.07^{* *}$ & $0.65^{* *, \mathrm{c}}$ & $0.81^{* *}$ & 0.49 & 0.39 & $0.37^{* *, c}$ & $3.86^{* *}$ & -0.48 & 1.38 & -0.01 & 24.62 \\
\hline 1990 & $-0.09^{* *}$ & $0.73^{* *, \mathrm{~b}}$ & $0.68^{* *}$ & $1.55^{* *}$ & $0.73^{*}$ & $0.85^{* *, \mathrm{c}}$ & $1.86^{* *}$ & -1.57 & $2.52^{*}$ & $-0.27^{* *}$ & 29.55 \\
\hline 1991 & 0.03 & $1.47^{* *, \mathrm{c}}$ & $0.42^{*}$ & $0.95^{* *}$ & $1.62^{* *}$ & $0.62^{* *, c}$ & $2.95^{* *}$ & 0.02 & -0.87 & $-0.34^{* *}$ & 26.38 \\
\hline 1992 & 0.00 & $0.99^{* *, b}$ & $0.72^{* *}$ & $1.06^{* *}$ & $2.56^{* *}$ & $0.23^{* *, \mathrm{c}}$ & $3.23^{* *}$ & -1.38 & $3.98^{* *}$ & $-0.14^{* *}$ & 27.14 \\
\hline 1993 & $0.10^{* *}$ & $0.12^{\mathrm{C}}$ & $0.88^{* *}$ & $1.48^{* *}$ & $0.72^{*}$ & $0.49^{* *, c}$ & $3.12^{* *}$ & -0.02 & $4.03^{* *}$ & $-0.08^{* *}$ & 20.40 \\
\hline 1994 & -0.01 & $1.27^{* *, \mathrm{~b}}$ & 0.16 & $0.91^{* *}$ & $1.45^{* *}$ & $0.08^{*, c}$ & $2.62^{* *}$ & 1.11 & $6.72^{* *}$ & $-0.07^{* *}$ & 19.17 \\
\hline 1995 & $0.14^{* *}$ & $1.25^{* *, \mathrm{~b}}$ & 0.31 & $2.23^{* *}$ & $0.92^{* *}$ & $0.45^{* *, \mathrm{c}}$ & $3.08^{* *}$ & -0.22 & $3.18^{* *}$ & -0.01 & 22.86 \\
\hline 1996 & 0.00 & $2.01^{* *, \mathrm{c}}$ & -0.06 & $1.68^{* *}$ & $0.92^{* *}$ & $0.26^{* *, c}$ & $2.18^{* *}$ & 1.04 & $5.99^{* *}$ & 0.11 & 22.60 \\
\hline 1997 & $0.06^{* *}$ & $1.95^{* *, \mathrm{c}}$ & 0.08 & $1.78^{* *}$ & $1.96^{* *}$ & $0.20^{* *, \mathrm{c}}$ & $2.45^{* *}$ & $2.19^{*}$ & $4.99^{* *}$ & $-0.18^{* *}$ & 25.47 \\
\hline 1998 & $-0.05^{* *}$ & $0.46^{* *, \mathrm{c}}$ & $0.81^{* *}$ & $1.28^{* *}$ & $1.41^{* *}$ & $0.33^{* *, \mathrm{c}}$ & $3.59^{* *}$ & 1.29 & $2.56^{*}$ & 0.06 & 15.50 \\
\hline 1999 & 0.05 & $-0.91^{\mathrm{c}}$ & $1.14^{* *}$ & $1.05^{*}$ & $2.67^{* *}$ & $0.62^{* *, \mathrm{c}}$ & $2.43^{* *}$ & $5.33^{* *}$ & $5.68^{* *}$ & 0.06 & 15.14 \\
\hline 2000 & -0.04 & $1.75^{* *, c}$ & $0.37^{*}$ & $1.35^{* *}$ & -0.29 & $0.30^{* *, c}$ & $3.54^{* *}$ & -1.82 & $3.64^{*}$ & $-0.15^{* *}$ & 16.15 \\
\hline 2001 & $0.07^{* *}$ & $1.10^{* *, b}$ & $0.40^{* *}$ & 0.58 & $1.85^{* *}$ & $0.01^{\mathrm{c}}$ & $2.07^{* *}$ & -1.11 & 1.11 & $-0.15^{* *}$ & 14.91 \\
\hline $\begin{array}{l}\text { Average }^{\mathrm{a}} \\
\text { 1983-2001 }\end{array}$ & $\begin{array}{c}0.04 \\
(1.69)\end{array}$ & $\begin{array}{c}1.01^{* *, \mathrm{~b}} \\
(6.41)\end{array}$ & $\begin{array}{l}0.36^{* *} \\
(3.67)\end{array}$ & $\begin{array}{l}1.09^{* *} \\
(8.91)\end{array}$ & $\begin{array}{l}1.27^{* *} \\
(7.59)\end{array}$ & $\begin{array}{c}0.30^{* *, c} \\
(5.49)\end{array}$ & $\begin{array}{l}2.46^{* *} \\
(11.47)\end{array}$ & $\begin{array}{c}0.35 \\
(0.91)\end{array}$ & $\begin{array}{l}2.79^{* *} \\
(5.67)\end{array}$ & $\begin{array}{l}-0.07^{*} \\
(-2.50)\end{array}$ & \\
\hline $\begin{array}{c}\text { Predicted } \\
\text { value/sign }\end{array}$ & $+/-$ & +1 & + & + & + & +1 & + & + & + & - & \\
\hline
\end{tabular}

${ }^{\text {a }}$ Numbers in parentheses are $t$-values based on the Fama-MacBeth approach.

${ }^{b}$ The coefficient is not significantly different from the predicted value of one at the $5 \%$ level.

${ }^{\mathrm{c}}$ The coefficient is significantly different from the predicted value of one at the $5 \%$ level. 
Table 3 Continued

Panel C. Earnings-based benchmark model (8)

\begin{tabular}{|c|c|c|c|c|}
\hline Year & Intercept & $x$ & $\Delta x$ & Adj. $R^{2}(\%)$ \\
\hline 1983 & $0.12^{* *}$ & $0.98^{* *}$ & 0.06 & 8.17 \\
\hline 1984 & -0.02 & $1.70^{* *}$ & -0.18 & 27.58 \\
\hline 1985 & $0.14^{* *}$ & $1.34^{* *}$ & $0.48^{* *}$ & 18.98 \\
\hline 1986 & $0.18^{* *}$ & $1.00^{* *}$ & $0.66^{* *}$ & 14.47 \\
\hline 1987 & $-0.10^{* *}$ & $0.57^{* *}$ & $0.44^{* *}$ & 5.65 \\
\hline 1988 & $0.08^{* *}$ & $0.91^{* *}$ & $0.54^{* *}$ & 11.92 \\
\hline 1989 & $0.07^{* *}$ & $0.68^{* *}$ & $1.06^{* *}$ & 14.47 \\
\hline 1990 & -0.02 & $0.79^{* *}$ & $1.05^{* *}$ & 15.39 \\
\hline 1991 & $0.28^{* *}$ & $1.25^{* *}$ & $0.78^{* *}$ & 12.79 \\
\hline 1992 & $0.09^{* *}$ & $0.91^{* *}$ & $1.40^{* *}$ & 19.17 \\
\hline 1993 & $0.14^{* *}$ & $0.50^{* *}$ & $1.12^{* *}$ & 8.67 \\
\hline 1994 & $-0.05^{* *}$ & $1.12^{* *}$ & $0.61^{* *}$ & 10.68 \\
\hline 1995 & $0.21^{* *}$ & $1.13^{* *}$ & $1.10^{* *}$ & 14.00 \\
\hline 1996 & $0.07^{* *}$ & $1.96^{* *}$ & $0.58^{* *}$ & 16.05 \\
\hline 1997 & $0.16^{* *}$ & $2.08^{* *}$ & $0.86^{* *}$ & 17.68 \\
\hline 1998 & $-0.06^{* *}$ & $0.74^{* *}$ & $0.99^{* *}$ & 7.64 \\
\hline 1999 & $0.12^{* *}$ & -0.66 & $1.89^{* *}$ & 5.63 \\
\hline 2000 & $0.08^{* *}$ & $1.76^{* *}$ & $0.51^{* *}$ & 10.39 \\
\hline 2001 & $0.06^{* *}$ & $1.46^{* *}$ & $0.32^{* *}$ & 12.53 \\
\hline $\begin{array}{c}\text { Average }^{\mathrm{a}} \\
\text { 1983-2001 }\end{array}$ & $\begin{array}{l}0.08^{* *} \\
(3.73)\end{array}$ & $\begin{array}{l}1.07^{* *} \\
(7.50)\end{array}$ & $\begin{array}{l}0.75^{* *} \\
(6.83)\end{array}$ & \\
\hline $\begin{array}{l}\text { Predicted } \\
\text { sign }\end{array}$ & $+/-$ & + & + & 10.20 \\
\hline
\end{tabular}

${ }^{\text {a }}$ Numbers in parentheses are $t$-values based on the Fama-MacBeth approach. 
Table 4. Incremental explanatory power of fundamental factors based on the pooled sample.

This table reports the incremental explanatory power (IEP) of fundamental factors based on the following return model:

$$
R_{i t}=\alpha+\beta x_{i t}+\gamma \Delta \hat{q}_{i t}+\gamma_{M} M \Delta \hat{q}_{i t}+\gamma_{H} H \Delta \hat{q}_{i t}+\delta \Delta \hat{b}_{i t}+\omega \Delta \hat{g}_{i t}+\omega_{M} M \Delta \hat{g}_{i t}+\omega_{H} H \Delta \hat{g}_{i t}+\varphi \Delta \hat{r}_{i t}+e_{i t} \text {. }
$$

The IEP of earnings yield ( $x$ ) equals the $\mathrm{R}^{2}$ of Model (7) minus the $\mathrm{R}^{2}$ of Model (7) excluding $x$, and the IEP of $(x, \Delta \hat{q})$ equals the $\mathrm{R}^{2}$ of Model (7) minus the $\mathrm{R}^{2}$ of Model (7) excluding $(x, \Delta \hat{q})$. The IEP for other factors are similarly defined. See Table 2 for the definitions of the regression variables. All $\mathrm{R}^{2} \mathrm{~s}$ refer to unadjusted- $\mathrm{R}^{2}$ s. The pooled sample consists of 27,897 firm-year observations for the period $1983-$ 2001. ${ }^{*}$ and ${ }^{* *}$ denote significance at the $5 \%$ and $1 \%$ levels, respectively, based on the $\mathrm{F}$ - or $\mathrm{t}$-statistic.

\begin{tabular}{lcc}
\hline & $\begin{array}{c}\mathrm{R}^{2} \text { of } \\
\text { Model }(7)\end{array}$ & IEP (\%) \\
\hline $\begin{array}{l}\text { Subset of factors } \\
\text { Cash flow factors }(x, \Delta \hat{q}, \Delta \hat{b}, \Delta \hat{g})\end{array}$ & 17.43 & $15.75^{* *}(\mathrm{~F}=662.9)$ \\
Profitability-related $(x, \Delta \hat{q})$ & 17.43 & $9.45^{* *}(\mathrm{~F}=794.2)$ \\
Scale-related $(\Delta \hat{b}, \Delta \hat{g})$ & 17.43 & $4.00^{* *}(\mathrm{~F}=334.9)$ \\
Discount rate change $(\Delta \hat{r})$ & 17.43 & $2.21^{* *}(\mathrm{~F}=734.9)$ \\
Single factor & & \\
Earnings yield $(x)$ & 17.43 & $2.84^{* *}(\mathrm{t}=30.8)$ \\
Profitability change $(\Delta \hat{q}, M \Delta \hat{q}, H \Delta \hat{q})$ & 17.43 & $2.31^{* *}(\mathrm{~F}=256.3)$ \\
Capital investment $(\Delta \hat{b})$ & 17.43 & $1.65^{* *}(\mathrm{t}=23.35)$ \\
Growth opportunity change $(\Delta \hat{g}, M \Delta \hat{g}, H \Delta \hat{g})$ & 17.43 & $2.28^{* *}(\mathrm{~F}=252.1)$ \\
Discount rate change $(\Delta \hat{r})$ & 17.43 & $2.21^{* *}(\mathrm{t}=-27.1)$ \\
\hline
\end{tabular}


Table 5. Results from abnormal return regressions

This table reports the results for the following regression models:

$$
\begin{aligned}
& \text { Model (6'): } A R_{i t}=\alpha+\beta x_{i t}+\gamma \Delta \hat{q}_{i t}+\delta \Delta \hat{b}_{i t}+\omega \Delta \hat{g}_{i t}+\varphi \Delta \hat{r}_{i t}+e_{i t} ; \\
& \text { Model (7'): } A R_{i t}=\alpha+\beta x_{i t}+\gamma \Delta \hat{q}_{i t}+\gamma_{M} M \Delta \hat{q}_{i t}+\gamma_{H} H \Delta \hat{q}_{i t}+\delta \Delta \hat{b}_{i t}+\omega \Delta \hat{g}_{i t}+\omega_{M} M \Delta \hat{g}_{i t}+\omega_{H} H \Delta \hat{g}_{i t}+\varphi \Delta \hat{r}_{i t}+e_{i t} ; \\
& \text { Model (8'): } A R_{i t}=\alpha+\beta x_{i t}+\lambda \Delta x_{i t}+e_{i t} .
\end{aligned}
$$

$A R_{i \mathrm{t}}$ is the abnormal annual stock return for firm $i$ in year $t$, measured by the residuals from regressing the total stock return on the three Fama-French factors. All independent variables are as defined in Table $2 .^{*}$ and ${ }^{* *}$ indicate significance at the $5 \%$ and the $1 \%$ levels,

\begin{tabular}{|c|c|c|c|c|c|c|c|}
\hline \multirow{3}{*}{$\begin{array}{l}\text { Variable } \\
\text { Intercept }\end{array}$} & \multirow{3}{*}{$\begin{array}{l}\begin{array}{l}\text { Predicted } \\
\text { sign }\end{array} \\
+/-\end{array}$} & \multirow{2}{*}{\multicolumn{2}{|c|}{$\frac{\text { Model (6') }}{\text { Estimate (t-value) }}$}} & \multirow{2}{*}{\multicolumn{2}{|c|}{$\begin{array}{c}\text { Model (7’) } \\
\text { Estimate (t-value) }\end{array}$}} & \multirow{2}{*}{\multicolumn{2}{|c|}{$\frac{\text { Model (8’) }}{\text { Estimate (t-value) }}$}} \\
\hline & & & & & & & \\
\hline & & $-0.10^{* *}$ & $(-24.65)$ & $-0.12^{* *}$ & $(-28.03)$ & $-0.14^{* *}$ & $(-37.38)$ \\
\hline$x$ & + & $0.51^{* *}$ & (11.86) & $0.62^{* *}$ & (14.31) & $0.73^{* *}$ & (18.93) \\
\hline$\Delta x$ & + & & & & & $0.54^{* *}$ & (15.37) \\
\hline$\Delta \hat{q}$ & + & $0.81^{* *}$ & (17.66) & $0.38^{* *}$ & (7.17) & & \\
\hline$M \Delta \hat{q}$ & + & & & $1.25^{* *}$ & (11.43) & & \\
\hline$H \Delta \hat{q}$ & + & & & $1.37^{* *}$ & (11.56) & & \\
\hline$\Delta b$ & + & $-0.10^{* *}$ & $(-6.59)$ & $-0.11^{* *}$ & $(-6.61)$ & & \\
\hline$\Delta \hat{g}$ & + & $2.26^{* *}$ & (16.23) & $1.99^{* *}$ & (11.45) & & \\
\hline$M \Delta \hat{g}$ & + & & & 0.26 & (0.39) & & \\
\hline$H \Delta \hat{g}$ & + & & & $2.10^{* *}$ & (5.12) & & \\
\hline$\Delta \hat{r}$ & - & $-0.03^{* *}$ & $(-7.34)$ & $-0.03^{* *}$ & $(-6.88)$ & & \\
\hline \multicolumn{2}{|c|}{ Adj. $R^{2}(\%)$} & \multicolumn{2}{|c|}{$5.18^{a}$} & \multicolumn{2}{|c|}{$6.08^{a}$} & \multicolumn{2}{|c|}{3.63} \\
\hline
\end{tabular}
respectively.

Panel A: Results from the pooled sample

a Vuong's Z-tests for comparing the models (6') and (7') with (8') yield statistics of 6.98 and 8.81, respectively, both significant at the $1 \%$ level, in favor of (6') and (7’) over (8'). 
Panel B: Average results from annual samples (1983 - 2001)

i) Model (6')

\begin{tabular}{|c|c|c|c|c|c|c|c|}
\hline Variable & $\begin{array}{l}\text { Inter- } \\
\text { cept }\end{array}$ & $x$ & $\Delta \hat{q}$ & $\Delta b$ & $\Delta \hat{g}$ & $\Delta \hat{r}$ & \multirow{2}{*}{$\begin{array}{c}\text { Average } \\
\text { adj. R² (\%) }\end{array}$} \\
\hline Predicted sign & $+/-$ & + & + & + & + & - & \\
\hline $\begin{array}{l}\text { Average coef. }{ }^{\mathrm{a}} \\
\text { 1983-2001 }\end{array}$ & $\begin{array}{l}-0.17^{* *} \\
(-7.73)\end{array}$ & $\begin{array}{l}0.45^{* *} \\
(3.58)\end{array}$ & $\begin{array}{l}0.88^{* *} \\
(9.13)\end{array}$ & $\begin{array}{c}-0.06 \\
(-1.10)\end{array}$ & $\begin{array}{l}2.30^{* *} \\
(8.21)\end{array}$ & $\begin{array}{c}-0.05 \\
(-1.20)\end{array}$ & 9.55 \\
\hline
\end{tabular}

ii) Model (7’)

\begin{tabular}{|c|c|c|c|c|c|c|c|c|c|c|c|}
\hline Variable & $\begin{array}{c}\text { Inter- } \\
\text { cept }\end{array}$ & $x$ & $\Delta \hat{q}$ & $M \Delta \hat{q}$ & $H \Delta \hat{q}$ & $\Delta b$ & $\Delta \hat{g}$ & $M \Delta \hat{g}$ & $H \Delta \hat{g}$ & $\Delta \hat{r}$ & \multirow{2}{*}{$\begin{array}{c}\text { Average } \\
\text { adj. } R^{2}(\%)\end{array}$} \\
\hline Predicted sign & $+/-$ & + & + & + & + & + & + & + & + & - & \\
\hline $\begin{array}{l}\text { Average coef. }{ }^{\text {a }} \\
\text { 1983-2001 }\end{array}$ & $\begin{array}{l}-0.17^{* *} \\
(-8.57)\end{array}$ & $\begin{array}{l}0.55^{* *} \\
(4.43)\end{array}$ & $\begin{array}{l}0.49^{* *} \\
(5.84)\end{array}$ & $\begin{array}{l}1.23^{* *} \\
(7.36)\end{array}$ & $\begin{array}{l}1.27^{* *} \\
(7.86)\end{array}$ & $\begin{array}{c}-0.07 \\
(-1.31)\end{array}$ & $\begin{array}{l}1.97^{* *} \\
(6.24)\end{array}$ & $\begin{array}{c}0.05 \\
(0.17)\end{array}$ & $\begin{array}{l}2.38^{* *} \\
(3.57)\end{array}$ & $\begin{array}{c}-0.04 \\
(-1.12)\end{array}$ & 10.93 \\
\hline
\end{tabular}

iii) Model (8')

\begin{tabular}{c|cccc}
\hline Variable & $\begin{array}{c}\text { Inter- } \\
\text { cept }\end{array}$ & $x$ & $\Delta x$ & $\begin{array}{c}\text { Average } \\
\text { adj. } \mathrm{R}^{2}(\%)\end{array}$ \\
\hline Predicted sign & $+/-$ & + & + & \\
\hline $\begin{array}{c}\text { Average coef. } \\
\text { 1983-2001 }\end{array}$ & $\begin{array}{c}-0.13^{* *} \\
(-9.13)\end{array}$ & $\begin{array}{c}0.64^{* *} \\
(5.20)\end{array}$ & $\begin{array}{c}0.70^{* *} \\
(9.13)\end{array}$ & 5.48 \\
\hline
\end{tabular}

${ }^{a}$ These are average coefficients from 19 annual regressions from 1983 to 2001 . Numbers in parentheses are Fama-MacBeth $t$-values. 